\title{
SUPPORTING INFORMATION \\ Optimization of 2-Amino-4,6-diarylpyrimidine-5-carbonitriles as Potent and Selective A1 Antagonists
}

\author{
Cristina Val, ${ }^{1,2 \S}$ Carlos Rodríguez-García, ${ }^{1,2 \S}$ Rubén Prieto-Díaz, ${ }^{1,2,5}$ Abel Crespo, ${ }^{1,2}$ Jhonny \\ Azuaje, ${ }^{1,2}$ Carlos Carbajales, ${ }^{1,2}$ Maria Majellaro, ${ }^{1,2}$ Alejandro Díaz-Holguín, ${ }^{5}$ José M. Brea, ${ }^{3 *}$ Maria \\ Isabel Loza,${ }^{3}$ Claudia Gioé-Gallo, ${ }^{1,2}$ Marialessandra Contino, ${ }^{4}$ Angela Stefanachi, ${ }^{4}$ Xerardo García- \\ Mera, ${ }^{2}$ Juan C. Estévez, ${ }^{1}$ Hugo Gutiérrez-de-Terán, ${ }^{*}$ and Eddy Sotelo ${ }^{1,2 *}$
}

\begin{abstract}
${ }^{1}$ Centro Singular de Investigación en Química Biolóxica e Materiais Moleculares (CiQUS) and ${ }^{2}$ Departamento de Química Orgánica, Universidade de Santiago de Compostela, Santiago de Compostela, 15782, Spain. ${ }^{3}$ Centro Singular de Investigación en Medicina Molecular y Enfermedades Crónicas (CiMUS). Universidade de Santiago de Compostela, Santiago de Compostela, 15782, Spain. ${ }^{4}$ Dipartimento di Farmacia-Scienze del Farmaco, Università degli Studi di Bari ALDO MORO, via Orabona 4, Bari, 70125, Italy. ${ }^{5}$ Department of Cell and Molecular Biology, Uppsala University, Uppsala 75124, Sweden.
\end{abstract}

$\S$ These authors contributed equally to this work

\footnotetext{
*To whom correspondence should be addressed:

(ES) +34 881815732, Fax.: +34-881815704, e-mail: e.sotelo@ $\underline{\text { usc.es }}$

(HGT) +46(0)184715056, e-mail: hugo.gutierrez@icm.uu.se

(JB): +34 881815459, Fax.: +34-8818115474, e-mail: pepo.brea@usc.es
}

\section{TABLE OF CONTENTS}

Chemistry. General information. S2

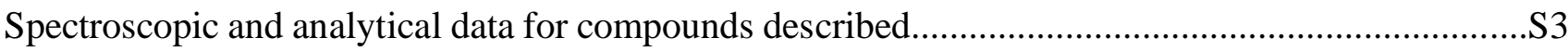

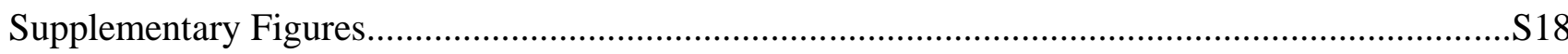

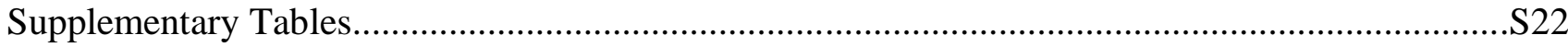

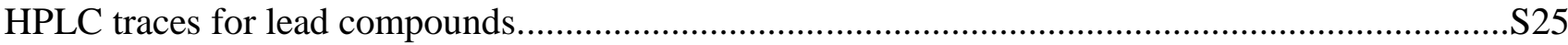

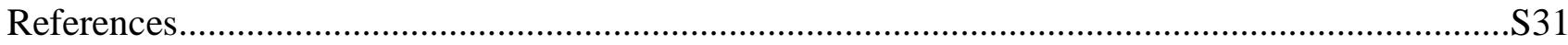




\section{Chemistry. General information}

Commercially available starting materials, reagents and solvents were purchased and used without further purification. The reactions were monitored by thin-layer chromatography (TLC) with $2.5 \mathrm{~mm}$ Merck silica gel GF 254 strips, and the purified compounds each showed a single spot; unless stated otherwise, UV light, $p$-anisaldehyde solution and/or iodine vapor were used for detection of compounds. The Biginelli reactions were performed in coated Kimble vials on a PLS (6X4) Organic Synthesizer with orbital stirring. Purity and identity of all tested compounds were established by a combination of mass spectrometry, HRMS and NMR spectra as described below. Purification of isolated products was carried out by column chromatography (Kieselgel $0.040-0.063 \mathrm{~mm}$, E. Merck) or medium pressure liquid chromatography (MPLC) on a ComBiFlash Companion (Teledyne ISCO) with RediSep pre-packed normal-phase silica gel (35-60 $\mu \mathrm{m})$ columns. Melting points were determined on a Stuart Scientific melting point apparatus and are uncorrected.

The NMR spectra were recorded on Bruker AM300 and XM500 spectrometers. Chemical shifts are given as $\delta$ values against tetramethylsilane as internal standard and $\mathrm{J}$ values are given in $\mathrm{Hz}$. Mass spectra were obtained on a Varian MAT-711 instrument. High-resolution mass spectra were obtained on an Autospec Micromass spectrometer. The purity of all tested compounds was determined to be $>95 \%$. All reported compounds are $>95 \%$ pure by HPLC analysis. HPLC traces obtained for representative lead compounds herein identified are provided in the supporting information. The structural and spectroscopic data obtained for all compounds described is provided.

\section{General procedure for the three-component synthesis of 2-Amino-4,6-diarylpyrimidin-5-} carbonitriles (18-20). A mixture of $\alpha$-cyanoketone 21a-j (1 mmol), aldehyde 22a-j (1 mmol), the guanidine salt 23a-d $(1.2 \mathrm{mmol})$ and $\mathrm{Na}_{2} \mathrm{CO}_{3}(3 \mathrm{mmol})$ in $3 \mathrm{~mL}$ of THF in coated Kimble vials was stirred with orbital stirring at $80^{\circ} \mathrm{C}$ for $12 \mathrm{~h}$. After completion of the reaction (controlled by TLC), the solvent is evaporated to dryness, the resulting residue is resuspended in water and extracted with ethyl acetate. The organic phase is dried with $\mathrm{Na}_{2} \mathrm{SO}_{4}$ and evaporated to dryness, when the oily residue is resuspended with methanol the product generally precipitates, is filtered and purified by recrystallization or column chromatography (silica gel) generally using Hexane/AcOEt mixtures as eluent. 


\section{Spectroscopic and analytical data for compounds described}

2-amino-4,6-diphenylpyrimidine-5-carbonitrile (18a). ${ }^{1}$ Yield: $58 \%$. Mp 214-216 ${ }^{\circ} \mathrm{C}{ }^{1} \mathrm{H}$ NMR (300 MHz, $\left.\mathrm{CDCl}_{3}\right), \delta(\mathrm{ppm}): 7.94-7.91(\mathrm{~m}, 4 \mathrm{H}), 7.57-7.49(\mathrm{~m}, 6 \mathrm{H}), 5.93$ (brs, 2H). ${ }^{13} \mathrm{C} \mathrm{NMR}$ (75 MHz, $\left.\mathrm{CDCl}_{3}\right) \delta(\mathrm{ppm}): 171.0,162.0,135.9,131.1,128.7,128.5,117.8,71.6$. HRMS (ESI) $\mathrm{m} / z$ calcd for $\mathrm{C}_{17} \mathrm{H}_{12} \mathrm{~N}_{4}[\mathrm{M}+\mathrm{H}]^{+}:$273.3040; found: 273.1140 .

2-amino-4-(2-fluorophenyl)-6-phenylpyrimidine-5-carbonitrile (18b). Yield: 47\%. Mp 207-208 ${ }^{\circ} \mathrm{C} .{ }^{1} \mathrm{H}$ NMR $\left(300 \mathrm{MHz}, \mathrm{CDCl}_{3}\right), \delta$ (ppm): 7.97-7.94 (m, 2H), 7.60-7.52 (m, 5H), 7.33-7.22 (m, 2H), 6.07 (brs, 2H). MS (EI) m/z: 290.1 (89, M+), 289.1 (100), 272.1 (27), 271.1 (52), 247.1 (10), 145.1 (24), 127.1 (12), 77.1 (11).

2-amino-4-(2-chlorophenyl)-6-phenylpyrimidine-5-carbonitrile (18c). Yield: 59\%. Mp 217-218 ${ }^{\circ} \mathrm{C} .{ }^{1} \mathrm{H}$ NMR (300 MHz, DMSO-d6), $\delta$ (ppm): 7.96 (s, 2H), 7.93-7.78 (m, 4H), 7.65-7.53 (m, 5H). MS (EI) $m / z: 308.1$ (22) 307.1 (33), $306.1\left(\mathrm{M}^{+}, 37\right), 305.1$ (100), 304 (36).

2-amino-4-(2-methoxyphenyl)-6-phenylpyrimidine-5-carbonitrile (18d). Yield: 75\%. Mp 198-199 ${ }^{\circ} \mathrm{C} .{ }^{1} \mathrm{H}$ NMR $\left(300 \mathrm{MHz}, \mathrm{CDCl}_{3}\right), \delta(\mathrm{ppm}): 8.16-8.10(\mathrm{~m}, 2 \mathrm{H}), 7.99(\mathrm{dd}, J=8.3,1.3 \mathrm{~Hz}, 1 \mathrm{H})$, $7.56-7.48(\mathrm{~m}, 2 \mathrm{H}), 7.44-7.37(\mathrm{~m}, 2 \mathrm{H}), 7.23(\mathrm{td}, J=7.5,1.3 \mathrm{~Hz}, 1 \mathrm{H}), 6.85(\mathrm{dd}, J=7.7,1.3 \mathrm{~Hz}, 1 \mathrm{H})$, 5.71 (brs, 2H), 3.94 (s, 3H). HRMS (EI) $m / z$ calcd for $\mathrm{C}_{18} \mathrm{H}_{14} \mathrm{~N}_{4} \mathrm{O}\left[\mathrm{M}^{+}\right]$: 302.1168; found: 302.1090 .

2-amino-4-(3-fluorophenyl)-6-phenylpyrimidine-5-carbonitrile (18e). Yield: 70\%. Mp 245-246 ${ }^{\circ} \mathrm{C} .{ }^{1} \mathrm{H}$ NMR (300 MHz, DMSO- $d 6$ ), $\delta$ (ppm): 7.96 (bs, 2H), 7.89-7.85 (m, 2H), 7.73-7.54 (m, $6 \mathrm{H}), 7.53-7.40(\mathrm{~m}, 1 \mathrm{H}) .{ }^{13} \mathrm{C}$ NMR (75 MHz, DMSO-d6) $\delta$ (ppm): 170.7, 169.4, 163.8, 162.8, 159.9, 138.9, 136.5, 131.0, 128.8, 128.5, 125.1, 118.4, 117.9, 115.9, 91.2. HRMS (ESI) m/z calcd for $\mathrm{C}_{17} \mathrm{H}_{11} \mathrm{FN}_{4}[\mathrm{M}+\mathrm{H}]^{+}:$291.1046; found: 291.1041 .

2-amino-4-(3-chlorophenyl)-6-phenylpyrimidine-5-carbonitrile (18f). Yield: 59\%. Mp 261-262 ${ }^{\circ}$ C. ${ }^{1} \mathrm{H}$ NMR (300 MHz, DMSO- $\left.d_{6}\right), \delta(\mathrm{ppm}):$ 8.70-7.69 (m, 6H), 7.71-7.43 (m, 5H). MS (EI) $m / z: 307.2$ (33), $306.2\left(\mathrm{M}^{+}, 92\right), 305.1$ (100), 288.1 (42), 271.1 (85), 254.1 (42).

2-amino-4-(3-methoxyphenyl)-6-phenylpyrimidine-5-carbonitrile (18g). Yield: $75 \%$. Mp 196-198 ${ }^{\circ}$ C. ${ }^{1} \mathrm{H}$ NMR (300 MHz, DMSO- $\left.d_{6}\right), \delta$ (ppm): 7.97-7.83 (m, 4H), 7.61-7.40 (m, 6H), 7.19-7.12 (m, 1H), 3.83 (s, 3H). HRMS (EI) $m / z$ : calcd for $\mathrm{C}_{18} \mathrm{H}_{14} \mathrm{~N}_{4} \mathrm{O}\left[\mathrm{M}^{+}\right]$: 302.1168, found: 302.1160 .

2-amino-4-(3-hydroxyphenyl)-6-phenylpyrimidine-5-carbonitrile (18h). Yield: $46 \%$. Mp 249-251 ${ }^{\circ} \mathrm{C} .{ }^{1} \mathrm{H}$ NMR (300 MHz, DMSO- $d_{6}$ ), $\delta$ (ppm): 9.75 (s, $\left.1 \mathrm{H}, \mathrm{OH}\right), 7.85-7.82$ (m, 4H), 7.55-7.52 
(m, 3H), 7.36-7.32 (m, 3H), 6.96-6.93 (m, 1H). ${ }^{13} \mathrm{C}$ NMR (75 MHz, DMSO- $\left.d 6\right) \delta(\mathrm{ppm}): 170.8,170.7$, $162.8,157.3,137.8,136.6,130.9,129.5,128.8,128.4,119.5,118.6,117.8,115.6,91.0$. HRMS (ESI) $m / z$ calcd for $\mathrm{C}_{17} \mathrm{H}_{12} \mathrm{~N}_{4} \mathrm{O}[\mathrm{M}+\mathrm{H}]^{+}: 289.1089$; found: 289.1084 .

2-amino-4-(3-cyanophenyl)-6-phenylpyrimidine-5-carbonitrile (18i). Yield: 39\%. Mp 218$219^{\circ} \mathrm{C} .{ }^{1} \mathrm{H}$ NMR (300 MHz, DMSO-d6), $\delta(\mathrm{ppm})$ : 8.37-8.14 (m, 2H), 8.14-7.95 (m, 3H), 7.95-7.72 (m, $3 \mathrm{H}), 7.67-7.50(\mathrm{~m}, 3 \mathrm{H}) .{ }^{13} \mathrm{C} \mathrm{NMR}\left(75 \mathrm{MHz}, \mathrm{CDCl}_{3}\right) \delta(\mathrm{ppm}): 170.6,168.9,162.8,137.7,136.4,134.3$, 133.5, 132.6, 131.1, 129.9, 128.8, 128.5, 118.3, 111.6, 95.1, 91.4. HRMS (ESI) $m / z$ calcd for $\mathrm{C}_{18} \mathrm{H}_{11} \mathrm{~N}_{5}$ $[\mathrm{M}+\mathrm{H}]^{+}:$298.1092, found: 298.1087 .

2-amino-4-(4-fluorophenyl)-6-phenylpyrimidine-5-carbonitrile (18j). Yield: 62\%. Mp 223$224^{\circ} \mathrm{C} .{ }^{1} \mathrm{H}$ NMR $\left(300 \mathrm{MHz}, \mathrm{CDCl}_{3}\right), \delta(\mathrm{ppm})$ : 8.02-7.92 (m, 4H), 7.57-7.51 (m, 3H), 7.25-7.19 (m, 2H), 5.60 (brs, 2H). $\left.{ }^{13} \mathrm{C} \mathrm{NMR} \mathrm{(75} \mathrm{MHz,} \mathrm{CDCl}_{3}\right) \delta$ (ppm): 115.67, 115.96, 118.02, 128.66, 128.83, 131.17, 131.31, 162.16, 166.28, 170.44, 171.84. HRMS (EI) $m / z$ : calcd for $\mathrm{C}_{17} \mathrm{H}_{11} \mathrm{FN}_{4}\left[\mathrm{M}^{+}\right]: 290.0968$, found: 290.0890 .

2-amino-4-(4-bromophenyl)-6-phenylpyrimidine-5-carbonitrile (18k). Yield: $43 \%$. Mp 218-219 ${ }^{\circ} \mathrm{C} .{ }^{1} \mathrm{H}$ NMR $\left(300 \mathrm{MHz}, \mathrm{CDCl}_{3}\right), \delta(\mathrm{ppm}):$ 7.97-7.90 (m, 2H), 7.88-7.80 (m, 2H), 7.71-7.64 (m, 2H), 7.59-7.50 (m, 3H), 5.69 (brs, 2H). MS (EI) m/z: 352 (96), 351 (100, M+), 350 (98), 349 (90, $\left.\mathrm{M}^{+}\right), 272$ (22), $271(91), 135$ (21).

2-amino-4-(4-methoxyphenyl)-6-phenylpyrimidine-5-carbonitrile (181). Yield: $61 \%$. Mp 185-187 ${ }^{\circ} \mathrm{C} .{ }^{1} \mathrm{H}$ NMR $\left(300 \mathrm{MHz}, \mathrm{CDCl}_{3}\right), \delta(\mathrm{ppm}):$ 8.01-7.91 (m, 4H), 7.55-7.52 (m, 3H), 7.26-7.02 (m, 2H), 5.60 (brs, 2H), 3.88 (s, 3H). $\left.{ }^{13} \mathrm{C} \mathrm{NMR} \mathrm{(75} \mathrm{MHz,} \mathrm{CDCl}_{3}\right) \delta$ (ppm): 171.86, 170.79, 162.19, $136.26,131.12$, 130.74, 129.58, 128.82, 128.60, 128.41, 118.46, 114.02, 92.89, 55.44. HRMS (EI) $m / z$ : calcd for $\mathrm{C}_{18} \mathrm{H}_{14} \mathrm{~N}_{4} \mathrm{O}\left[\mathrm{M}^{+}\right]$: 302.1168, found: 302.1169 .

2-amino-4-(4-hydroxyphenyl)-6-phenylpyrimidine-5-carbonitrile (18m). Yield: 69\%. Mp 292-293ㄷ․ ${ }^{1} \mathrm{H}$ NMR (300 MHz, DMSO-d6), $\delta$ (ppm): 10.14 (brs, 1H), 7.84-7.82 (m, 6H), 7.55-7.53 $(\mathrm{m}, 3 \mathrm{H}), 6.89(\mathrm{~d}, J=8.68,2 \mathrm{H})$. HRMS (EI) $\mathrm{m} / \mathrm{z}$ : calcd for $\mathrm{C}_{17} \mathrm{H}_{12} \mathrm{~N}_{4} \mathrm{O}\left[\mathrm{M}^{+}\right]$: 288.1011, found: 288.0932.

2-amino-4-phenyl-6-(p-tolyl)pyrimidine-5-carbonitrile (18n). Yield: 73\%. Mp 192-193ㅇ. ${ }^{1} \mathrm{H}$ NMR (300 MHz, $\left.\mathrm{CDCl}_{3}\right), \delta(\mathrm{ppm}): 7.93(\mathrm{~m}, 2 \mathrm{H}), 7.85(\mathrm{~d}, J=8.0 \mathrm{~Hz}, 2 \mathrm{H}), 7.54(\mathrm{~m}, 3 \mathrm{H}), 7.33(\mathrm{~m}$, 2H), 5.73 (brs, 2H), 2.48 (s, 3H). $\left.{ }^{13} \mathrm{C} \mathrm{NMR} \mathrm{(75} \mathrm{MHz,} \mathrm{CDCl}_{3}\right) \delta$ (ppm): 171.1, 170.8, 163.1, 141.3, 137.0, 134.1, 131.2, 129.3, 129.2, 128.7, 119.1, 91.2, 21.4. HRMS (ESI) $m / z$ : calcd for $\mathrm{C}_{18} \mathrm{H}_{14} \mathrm{~N}_{4}$ $[\mathrm{M}+\mathrm{H}]^{+}:$287.1296, found: 287.1291 .

2-amino-4-(2,4-difluorophenyl)-6-phenylpyrimidine-5-carbonitrile (18o). Yield: 75\%. Mp 152-156 ${ }^{\circ} \mathrm{C} .{ }^{1} \mathrm{H}$ NMR $\left(300 \mathrm{MHz}, \mathrm{CDCl}_{3}\right), \delta(\mathrm{ppm}):$ 7.98-7.95 (m, 2H), 7.57-7.53 (m, 4H), 7.06-7.00 (m, 2H), 5.69 (brs, 2H). MS (EI) m/z: 308.1 (M+, 99), 307.1 (100), 299.1 (94), 272.0 (30), 163.0 (21). 
2-amino-4-(2,4-dichlorophenyl)-6-phenylpyrimidine-5-carbonitrile (18p). Yield: 51\%. Mp 178-180 ${ }^{\circ} \mathrm{C} .{ }^{1} \mathrm{H}$ NMR $\left(300 \mathrm{MHz}, \mathrm{CDCl}_{3}\right), \delta(\mathrm{ppm})$ : 7.99-7.97 (m, 2H), 7.57-7.41 (m, 4H), 7.41 (s, 2H), 5.69 (brs, 2H). HRMS (EI) $\mathrm{m} / z$ : calcd for $\mathrm{C}_{17} \mathrm{H}_{10} \mathrm{Cl}_{2} \mathrm{~N}_{4}\left[\mathrm{M}^{+}\right]$: 340.0283 , found: 340.0283 .

2-amino-4-(2,4-dimethoxyphenyl)-6-phenylpyrimidine-5-carbonitrile (18q). Yield: 40\%. Mp 187-188 ${ }^{\circ} \mathrm{C} .{ }^{1} \mathrm{H}$ NMR (300 MHz, $\left.\mathrm{CDCl}_{3}\right), \delta(\mathrm{ppm})$ : 7.83-7.78 (m, 3H), 7.55-7.53 (m, 2H), $7.33(\mathrm{~d}$, $J=8.4 \mathrm{~Hz}, 1 \mathrm{H}), 6.71(\mathrm{~d}, J=1.8 \mathrm{~Hz}, 1 \mathrm{H}), 6.64(\mathrm{dd}, J=8.4,2.1 \mathrm{~Hz}, 1 \mathrm{H}), 3.86(\mathrm{~s}, 3 \mathrm{H}), 3.82(\mathrm{~s}, 3 \mathrm{H}) . \mathrm{MS}$ (EI) $m / z: 332.1\left(\mathrm{M}^{+}, 100\right), 331.0$ (92), 315.0 (27), 301,0 (37), 289.0 (29).

2-amino-4-(3,5-difluorophenyl)-6-phenylpyrimidine-5-carbonitrile (18r). Yield: 61\%. Mp 225-226 ${ }^{\circ} \mathrm{C} .{ }^{1} \mathrm{H}$ NMR (300 MHz, DMSO- $d_{6}$ ), $\delta$ (ppm): 10.42 (brs, 2H), $8.14-8.08$ (m, 2H), 7.71 (d, $J$ $=2.2 \mathrm{~Hz}, 2 \mathrm{H}), 7.56-7.48(\mathrm{~m}, 2 \mathrm{H}), 7.44-7.37(\mathrm{~m}, 1 \mathrm{H}), 7.01(\mathrm{t}, J=2.2 \mathrm{~Hz}, 1 \mathrm{H})$. HRMS (EI) $m / z$ : calcd for $\mathrm{C}_{17} \mathrm{H}_{10} \mathrm{~F}_{2} \mathrm{~N}_{4}\left[\mathrm{M}^{+}\right]$: 308.0874, found: 308.0876 .

2-amino-4-(3,5-dichlorophenyl)-6-phenylpyrimidine-5-carbonitrile (18s). Yield: 40\%. Mp 181-183 ${ }^{\circ} \mathrm{C} .{ }^{1} \mathrm{H}$ NMR (300 MHz, DMSO-d6), $\delta$ (ppm): 8.03 (s, 2H), 7.92-7.87 (m, 5H), 7.57-7.55 (m, 3H). MS (EI) $m / z: 340.01\left(\mathrm{M}^{+}, 100\right), 305.04$ (95), 288.0 (39), 152.0 (42).

2-amino-4-(3,5-dimethoxyphenyl)-6-phenylpyrimidine-5-carbonitrile (18t). Yield: 55\%. Mp 219-221 ${ }^{\circ} \mathrm{C} .{ }^{1} \mathrm{H}$ NMR (300 MHz, DMSO- $d_{6}$ ), $\delta$ (ppm): 7.90 (s, 2H), 7.89-7.80 (m, 2H), 7.67-7.47 $(\mathrm{m}, 3 \mathrm{H}), 7.20-7.11(\mathrm{~m}, 2 \mathrm{H}), 6.83-6.64(\mathrm{~m}, 1 \mathrm{H}), 3.79(\mathrm{~s}, 6 \mathrm{H})$. HRMS (EI) $m / z$ : calcd for $\mathrm{C}_{19} \mathrm{H}_{16} \mathrm{~N}_{4} \mathrm{O}_{2}$ $\left[\mathrm{M}^{+}\right]$: 332.1273 found: 332.1273 .

2-amino-4-(benzo $[d][1,3]$ dioxol-5-yl)-6-phenylpyrimidine-5-carbonitrile $\quad(18 u)$ Yield: 68\%. Mp 243-245 ${ }^{\circ} \mathrm{C} .{ }^{1} \mathrm{H}$ NMR (300 MHz, $\left.\mathrm{CDCl}_{3}\right), \delta(\mathrm{ppm}):$ 7.97-7.87 (m, 2H), 7.63-7.43 (m, 5H), $6.95(\mathrm{~d}, J=8.2 \mathrm{~Hz}, 1 \mathrm{H}), 6.06(\mathrm{~s}, 2 \mathrm{H}), 5.59$ (brs, $2 \mathrm{H})$. HRMS (EI) $m / z$ : calcd for $\mathrm{C}_{18} \mathrm{H}_{12} \mathrm{~N}_{4} \mathrm{O}_{2}\left[\mathrm{M}^{+}\right]$: 316.0960, found: 316.0959 .

2-amino-4-phenyl-6-(3,4,5-trimethoxyphenyl)pyrimidine-5-carbonitrile (18v). Yield: 50\%. Mp 185-186 ${ }^{\circ} \mathrm{C} .{ }^{1} \mathrm{H}$ NMR (300 MHz, DMSO- $\left.d_{6}\right), \delta(\mathrm{ppm}):$ 7.88-7.87 (m, 4H), 7.56-7.53 (m, 3H), $7.22(\mathrm{~s}, 2 \mathrm{H}), 3.83(\mathrm{~s}, 6 \mathrm{H}), 3.74(\mathrm{~s}, 3 \mathrm{H}) .{ }^{13} \mathrm{C} \mathrm{NMR}\left(75 \mathrm{MHz}, \mathrm{CDCl}_{3}\right) \delta(\mathrm{ppm}): 170.71,170.08,162.62$, $152.55,139.67,136.54,131.54,130.79,128.75,128.29,118.75,106.55,91.00,60.19$, 56.07 HRMS (EI) $m / z$ : calcd for $\mathrm{C}_{20} \mathrm{H}_{18} \mathrm{~N}_{4} \mathrm{O}_{3}\left[\mathrm{M}^{+}\right]: 362.1379$, found: 362.1381 .

2-amino-4-phenyl-6-(2,4,6-trifluorophenyl)pyrimidine-5-carbonitrile (18w). Yield: 41\%. Mp 226-227º C. ${ }^{1} \mathrm{H}$ NMR (300 MHz, DMSO- $\left.d_{6}\right), \delta(\mathrm{ppm}):$ 7.63-7.60 (m, 2H), 7.45-7.39 (m, 3H), 7.27 (dd, $J=8.7 \mathrm{~Hz}, 2 \mathrm{H}), 5.7$ (brs, 2H). MS (EI) m/z: 328.1 (40), 327.1 (16), $326.1\left(\mathrm{M}^{+}, 16\right), 307.1$ (16), $197.1(100)$

2-amino-4-(furan-2-yl)-6-phenylpyrimidine-5-carbonitrile (18x). Yield: 41\%. Mp 164$165^{\circ} \mathrm{C} .{ }^{1} \mathrm{H}$ NMR $\left(300 \mathrm{MHz}, \mathrm{CDCl}_{3}\right), \delta(\mathrm{ppm}): 7.97-7.83(\mathrm{~m}, 2 \mathrm{H}), 7.79(\mathrm{~d}, J=3.7 \mathrm{~Hz}, 1 \mathrm{H}), 7.73(\mathrm{~d}, J$ 
$=1.7 \mathrm{~Hz}, 1 \mathrm{H}), 7.65-7.41(\mathrm{~m}, 3 \mathrm{H}), 6.64(\mathrm{dd}, J=3.7,1.7 \mathrm{~Hz}, 1 \mathrm{H}), 5.73(\mathrm{brs}, 2 \mathrm{H}) . \mathrm{HRMS}(\mathrm{EI}) \mathrm{m} / z$ : calcd for $\mathrm{C}_{15} \mathrm{H}_{10} \mathrm{~N}_{4} \mathrm{O}\left[\mathrm{M}^{+}\right]$: 262.0855, found 262.0854.

2-amino-4-phenyl-6-(thiophen-2-yl)pyrimidine-5-carbonitrile (18y). Yield: 63\%. Mp 163$165^{\circ} \mathrm{C} .{ }^{1} \mathrm{H} \mathrm{NMR}\left(300 \mathrm{MHz}, \mathrm{CDCl}_{3}\right), \delta$ (ppm): 8.48 (dd, $\left.J=4.0,1.0 \mathrm{~Hz}, 1 \mathrm{H}\right), 7.92-7.85$ (m, 2H), 7.63$7.60(\mathrm{~m}, 1 \mathrm{H}), 7.56-7.52(\mathrm{~m}, 3 \mathrm{H}), 7.21$ (dd, $J=5.1,4.0 \mathrm{~Hz}, 1 \mathrm{H}), 5.54$ (brs, 2H). HRMS (EI) m/z: calcd for $\mathrm{C}_{15} \mathrm{H}_{10} \mathrm{~N}_{4} \mathrm{~S}\left[\mathrm{M}^{+}\right]$: 278.0626, found: 278.0627 .

2-amino-4-(furan-3-yl)-6-phenylpyrimidine-5-carbonitrile (18z). Yield: 74\%. Mp 182$184^{\circ} \mathrm{C}$. ${ }^{1} \mathrm{H}$ NMR $\left(300 \mathrm{MHz}, \mathrm{CDCl}_{3}\right), \delta$ (ppm): 8.49-8.47 (m, 1H), 7.90-7.87 (m, 2H), 7.62-7.59 (m, $1 \mathrm{H}), 7.56-7.51(\mathrm{~m}, 3 \mathrm{H}), 7.23-7.19(\mathrm{~m}, 1 \mathrm{H}), 5.52$ (brs, $2 \mathrm{H})$. HRMS (EI) $m / z$ calcd for $\mathrm{C}_{15} \mathrm{H}_{10} \mathrm{~N}_{4} \mathrm{O}\left[\mathrm{M}^{+}\right]$: 262.0855 found: 262.0857 .

2-amino-4-phenyl-6-(thiophen-3-yl)pyrimidine-5-carbonitrile (18aa). Yield: 48\%. Mp 181-182 ${ }^{\circ} \mathrm{C} .{ }^{1} \mathrm{H}$ NMR (300 MHz, DMSO-d6), $\delta(\mathrm{ppm}): 8.64$ (dd, $\left.J=1.6,1.0 \mathrm{~Hz}, 1 \mathrm{H}\right), 7.91-7.88$ (m, $3 \mathrm{H}), 7.55-7.51(\mathrm{~m}, 3 \mathrm{H}), 7.44-7.41(\mathrm{~m}, 1 \mathrm{H}), 5.60$ (bs, 2H). ${ }^{13} \mathrm{C}$ NMR (75 MHz, DMSO-d6) $\delta(\mathrm{ppm})$ : 171.1, 164.4, 162.9, 138.1, 136.6, 130.9, 130.1, 128.8, 128.4, 127.8, 127.1, 119.1, 89.8. HRMS (ESI) $m / z$ : calcd for $\mathrm{C}_{15} \mathrm{H}_{10} \mathrm{~N}_{4} \mathrm{~S}[\mathrm{M}+\mathrm{H}]^{+}: 279.0704$, found: 279.0699 .

2-amino-4-phenyl-6-(pyridin-4-yl)pyrimidine-5-carbonitrile (18ab). Yield: 49\%. Mp 266$267^{\circ} \mathrm{C} .{ }^{1} \mathrm{H}$ NMR (300 MHz, DMSO- $d 6$ ), $\delta(\mathrm{ppm}):$ 8.8-8.78 (m, 2H), 8.03 (s, 2H), 7.88-7.85 (m, 2H), 7.80-7.78 (m, 2H), 7.59-7.54 (m, 3H). ${ }^{13} \mathrm{C} \mathrm{NMR}\left(75 \mathrm{MHz}, \mathrm{CDCl}_{3}\right) \delta(\mathrm{ppm}): 168.77,162.77,150.03$, 143.70, 136.23, 136.02, 131.03, 128.70, 128.43, 122.80. MS (EI) $m / z: 273.1\left(\mathrm{M}^{+}, 98\right), 271.9$ (100).

2-amino-4-phenyl-6-(pyridin-3-yl)pyrimidine-5-carbonitrile (18ac). Yield: 68\%. Mp 243$244^{\circ} \mathrm{C} .{ }^{1} \mathrm{H}$ NMR (300 MHz, DMSO-d6), $\delta$ (ppm): 9.17 (d, $\left.J=1.6 \mathrm{~Hz}, 1 \mathrm{H}\right), 8.75-8.70(\mathrm{~m}, 1 \mathrm{H}), 8.28-$ $8.22(\mathrm{~m}, 1 \mathrm{H}), 8.10-8.01(\mathrm{~m}, 2 \mathrm{H}), 7.90-7.86(\mathrm{~m}, 2 \mathrm{H}), 7.62-7.55(\mathrm{~m}, 4 \mathrm{H}) .{ }^{13} \mathrm{C}$ NMR $(75 \mathrm{MHz}, \mathrm{DMSO}-$ $\left.d_{6}\right) \delta$ (ppm): 187.9, 170.6, 168.5, 162.9, 151.5, 149.2, 136.4, 132.5, 131.1, 128.8, 128.5, 123.5, 118.4, 91.5. HRMS (ESI) $m / z$ : calcd for $\mathrm{C}_{16} \mathrm{H}_{11} \mathrm{~N}_{5}[\mathrm{M}+\mathrm{H}]^{+}:$274.1093, found: 274.1087 .

2-amino-4-cyclopentyl-6-phenylpyrimidine-5-carbonitrile (18ad). Yield: 67\%. Mp 185$186^{\circ} \mathrm{C} .{ }^{1} \mathrm{H}$ NMR (300 MHz, $\left.\mathrm{CDCl}_{3}\right), \delta$ (ppm): 7.90-7.87 (m, 2H), 7.53-7.41 (m, 3H), 5.46 (brs, 2H), 2.27-1.52 (m, 9H). HRMS (EI) $m / z$ : calcd for $\mathrm{C}_{16} \mathrm{H}_{16} \mathrm{~N}_{4}\left[\mathrm{M}^{+}\right]$: 264.1375, found: 264.1303.

2-amino-4-cyclohexyl-6-phenylpyrimidine-5-carbonitrile (18ae). Yield: 46\%. Mp 186-187 ${ }^{\circ} \mathrm{C} .{ }^{1} \mathrm{H}$ NMR $\left(300 \mathrm{MHz}, \mathrm{CDCl}_{3}\right), \delta$ (ppm): 7.98-7.87 (m, 2H), 7.50-7.22 (m, 3H), 5.62 (brs, 2H), 3.11$2.99(\mathrm{~m}, 1 \mathrm{H}), 1.85-1.20(\mathrm{~m}, 10 \mathrm{H}) .{ }^{13} \mathrm{C} \mathrm{NMR}\left(75 \mathrm{MHz}, \mathrm{CDCl}_{3}\right) \delta(\mathrm{ppm}): 180.4,162.3,136.5,172.5$, $169.5,130.9$, 128.4, 117.2, 93.7, 44.3, 30.9, 25.8, 25.6. HRMS (ESI) $m / z$ : calcd for $\mathrm{C}_{17} \mathrm{H}_{18} \mathrm{~N}_{4}[\mathrm{M}+\mathrm{H}]^{+}$: 279.1610, found: 279.1604 . 
2-amino-4-(naphthalen-2-yl)-6-phenylpyrimidine-5-carbonitrile (18af). Yield: $44 \%$. Mp 199-201 ${ }^{\circ} \mathrm{C} .{ }^{1} \mathrm{H}$ NMR (300 MHz, $\left.\mathrm{CDCl}_{3}\right), \delta(\mathrm{ppm}): 8.51$ (s, 1H), 8.00-7.96 (m, 6H), 7.60-7.54 (m, 5H), 5.68 (brs, 2H). HRMS (EI) $m / z$ : calcd for $\mathrm{C}_{21} \mathrm{H}_{14} \mathrm{~N}_{4}\left[\mathrm{M}^{+}\right]$: 322.1218 , found: 322.1231 .

4-([1,1'-biphenyl]-4-yl)-2-amino-6-phenylpyrimidine-5-carbonitrile (18ag). Yield: 46\%. Mp 219-221 ${ }^{\circ} \mathrm{C} .{ }^{1} \mathrm{H}$ NMR (300 MHz, DMSO- $\left.d_{6}\right), \delta(\mathrm{ppm}): 8.00(\mathrm{~d}, J=7.8 \mathrm{~Hz}, 2 \mathrm{H}), 7.95-7.81(\mathrm{~m}, 5 \mathrm{H})$, 7.77 (d, $J=7.5 \mathrm{~Hz}, 2 \mathrm{H}), 7.62-7.35$ (m, 5H), 5.69 (brs, 2H). MS (EI) $m / z: 348.3\left(\mathrm{M}^{+}, 79\right), 347.3$ (100), $330.2(8)$.

2-amino-4,6-bis(3-chlorophenyl)pyrimidine-5-carbonitrile (18ah). Yield: 49\%. Mp 241$242^{\circ} \mathrm{C} .{ }^{1} \mathrm{H}$ NMR (300 MHz, DMSO- $\left.d_{6}\right), \delta(\mathrm{ppm}): 8.05$ (s, 2H), 7.99-7.78 (m, 4H), 7.77-7.50 (m, 4H). MS (EI) $m / z: 341.0\left(\mathbf{M}^{+}, 85\right), 306.0$ (100).

2-amino-4-(3-chlorophenyl)-6-(3,5-dichlorophenyl)pyrimidine-5-carbonitrile (18ai). Yield: 46\%. Mp 274-275 ${ }^{\circ} \mathrm{C} .{ }^{1} \mathrm{H}$ NMR (300 MHz, DMSO- $d 6$ ), $\delta$ (ppm): 8.11 (s, 2H), 7.93-7.84 (m, 5H), 7.66-7.59 (m, 2H). ${ }^{13} \mathrm{C} \mathrm{NMR}\left(75 \mathrm{MHz}, \mathrm{CDCl}_{3}\right) \delta$ (ppm): 169.1, 167.9, 162.8, 139.6, 138.3, 134.3, 133.3, 130.9, 130.6, 130.4, 128.6, 127.6, 127.5, 118.0, 91.5. HRMS (ESI) $m / z$ : calcd for $\mathrm{C}_{17} \mathrm{H}_{9} \mathrm{Cl}_{3} \mathrm{~N}_{4}$ $[\mathrm{M}+\mathrm{H}]^{+}:$374.9971, found: 374.9966 .

2-amino-4-(benzo[d][1,3]dioxol-5-yl)-6-(3-chlorophenyl)pyrimidine-5-carbonitrile (18aj). Yield: 55\%. Mp 262-263으. ${ }^{1} \mathrm{H}$ NMR (300 MHz, $\left.\mathrm{CDCl}_{3}\right), \delta(\mathrm{ppm}): 7.90-7.81$ (m, 2H), 7.62-7.41 (m, 4H), 6.95 (dd, $J=8.2,0.8 \mathrm{~Hz}, 1 \mathrm{H}), 6.06$ (s, 2H), 5.58 (brs, 2H). MS (EI) m/z: $350.1\left(\mathrm{M}^{+}, 100\right), 315.1$ (46), 146.0 (32).

\section{2-amino-4-(benzo[d][1,3] dioxol-5-yl)-6-(4-fluorophenyl)pyrimidine-5-carbonitrile} (18ak). Yield: 49\%. Mp 242-243ㄷ. ${ }^{1} \mathrm{H}$ NMR (300 MHz, $\left.\mathrm{CDCl}_{3}\right), \delta$ (ppm): 8.07-7.91 (m, 2H), 7.58 $(\mathrm{dd}, J=8.2,1.8 \mathrm{~Hz}, 1 \mathrm{H}), 7.44(\mathrm{~d}, J=1.8 \mathrm{~Hz}, 1 \mathrm{H}), 7.21(\mathrm{dd}, J=8.7 \mathrm{~Hz}, 2 \mathrm{H}), 6.95(\mathrm{~d}, J=8.2 \mathrm{~Hz}, 1 \mathrm{H})$, 6.06 (s, 2H), 5.56 (brs, 2H). HRMS (EI) $m / z$ : calcd for $\mathrm{C}_{18} \mathrm{H}_{11} \mathrm{FN}_{4} \mathrm{O}_{2}\left[\mathrm{M}^{+}\right]$: 334.0866, found: 334.0859 .

2-amino-4,6-bis(4-methoxyphenyl)pyrimidine-5-carbonitrile (18al). Yield: 66\%. Mp 320$322^{\circ} \mathrm{C} .{ }^{1} \mathrm{H}$ NMR (300 MHz, DMSO- $\left.d_{6}\right), \delta(\mathrm{ppm}): 7.94-7.83$ (m, 4H), 7.77 (s, 2H), 7.15-7.03 (m, 4H), 3.84 (s, 6H). HRMS (EI) $m / z$ : calcd for $\mathrm{C}_{19} \mathrm{H}_{16} \mathrm{~N}_{4} \mathrm{O}_{2}\left[\mathrm{M}^{+}\right]$: 332.1273, found 332.1259.

2-amino-4-(4-fluorophenyl)-6-(furan-2-yl)pyrimidine-5-carbonitrile (18am). Yield: 58\%. Mp 268-269 ${ }^{\circ} \mathrm{C} .{ }^{1} \mathrm{H}$ NMR (300 MHz, $\left.\mathrm{CDCl}_{3}\right), \delta(\mathrm{ppm}): 8.00-7.88(\mathrm{~m}, 2 \mathrm{H}), 7.78(\mathrm{~d}, J=3.6 \mathrm{~Hz}, 1 \mathrm{H})$, $7.73(\mathrm{~d}, J=1.5 \mathrm{~Hz}, 1 \mathrm{H}), 7.26-7.18(\mathrm{~m}, 2 \mathrm{H}), 6.65$ (dd, $J=3.6,1.7 \mathrm{~Hz}, 1 \mathrm{H}), 5.61$ (brs, 2H). HRMS (EI) $m / z$ : calcd for $\mathrm{C}_{15} \mathrm{H}_{9} \mathrm{FN}_{4} \mathrm{O}\left[\mathrm{M}^{+}\right]$: 280.0760, found: 280.0765 .

2-(methylamino)-4,6-diphenylpyrimidine-5-carbonitrile (19a). Yield: 57\%. Mp 214-216 ${ }^{\circ} \mathrm{C}$ .${ }^{1} \mathrm{H}$ NMR (300 MHz, $\left.\mathrm{CDCl}_{3}\right), \delta(\mathrm{ppm}): 8.05-7.89$ (m, 4H), 7.54-7.52 (m, 6H), $5.86(\mathrm{bs}, 1 \mathrm{H}), 3.11(\mathrm{~d}$, $J=5.1 \mathrm{~Hz}, 3 \mathrm{H}) .{ }^{13} \mathrm{C} \mathrm{NMR}\left(75 \mathrm{MHz}, \mathrm{CDCl}_{3}\right) \delta(\mathrm{ppm}): 171.0,161.7,136.3,131.0,128.9,128.6,118.5$, 91.7, 28.1. HRMS (ESI) $m / z$ : calcd for: $\mathrm{C}_{18} \mathrm{H}_{14} \mathrm{~N}_{4}[\mathrm{M}+\mathrm{H}]^{+}:$287.1296, found: 287.1291. 
2-(ethylamino)-4,6-diphenylpyrimidine-5-carbonitrile (19b). Yield: $75 \%$. Mp 178-180 ${ }^{\circ} \mathrm{C}$. ${ }^{1} \mathrm{H}$ NMR (300 MHz, $\left.\mathrm{CDCl}_{3}\right), \delta(\mathrm{ppm}): 8.02-7.90(\mathrm{~m}, 4 \mathrm{H}), 7.50-7.25(\mathrm{~m}, 6 \mathrm{H}), 5.86(\mathrm{t}, J=4.63,1 \mathrm{H})$, $3.58(\mathrm{~m}, 2 \mathrm{H}), 1.26(\mathrm{t}, J=7.2,3 \mathrm{H}) .{ }^{13} \mathrm{C} \mathrm{NMR}\left(75 \mathrm{MHz}, \mathrm{CDCl}_{3}\right) \delta(\mathrm{ppm}): 171.0,161.1,136.3,130.8$, 128.9, 128.4, 118.5, 91.7, 36.3, 14.6. HRMS (EI) $m / z$ : calcd for $\mathrm{C}_{19} \mathrm{H}_{16} \mathrm{~N}_{4}\left[\mathrm{M}^{+}\right]$: 300.1375 , found: 300.3567 .

4,6-diphenyl-2-(phenylamino)pyrimidine-5-carbonitrile (19c). Yield: 73\%. Mp 165-167 ${ }^{\circ} \mathrm{C} .{ }^{1} \mathrm{H}$ NMR $\left(300 \mathrm{MHz}, \mathrm{CDCl}_{3}\right), \delta(\mathrm{ppm}):$ 8.04-8.02 (m, 4H), 7.76-7.68 (m, 3H), 7.60-7.55 (m, 6H), $7.38(\mathrm{dd}, J=7.5 \mathrm{~Hz}, 2 \mathrm{H}), 7.13(\mathrm{dd}, J=7.5 \mathrm{~Hz}, 1 \mathrm{H}) .{ }^{13} \mathrm{C}$ NMR $\left(75 \mathrm{MHz}, \mathrm{CDCl}_{3}\right) \delta(\mathrm{ppm}): 171.1$, 158.9, 138.0, 136.0, 131.2, 128.9, 128.8, 128.5, 123.8, 119.8, 118.0, 93.9. HRMS (ESI) $\mathrm{m} / \mathrm{z}$ : calcd for $\mathrm{C}_{23} \mathrm{H}_{16} \mathrm{~N}_{4}[\mathrm{M}+\mathrm{H}]^{+}:$349.1453, found: 349.1448 .

4-(2-fluorophenyl)-2-(methylamino)-6-phenylpyrimidine-5-carbonitrile (19d). Yield: 52\%. Mp 184-186 ${ }^{\circ} \mathrm{C} .{ }^{1} \mathrm{H}$ NMR (300 MHz, DMSO-d6), $\delta$ (ppm): 8.47 (bs, 1H), 7.95-7.83 (m, 2H), 7.72-7.59 (m, 5H), 7.45-7.37 (m, 2H), 2.96-2.89 (m, 3H). HRMS (EI) $m / z$ : calcd for $\mathrm{C}_{18} \mathrm{H}_{13} \mathrm{FN}_{4}\left[\mathrm{M}^{+}\right]$: 304.1124, found: 304.1139 .

4-(2-fluorophenyl)-6-phenyl-2-(phenylamino)pyrimidine-5-carbonitrile (19e). Yield: 67\%. Mp 132-134 ${ }^{\circ} \mathrm{C} .{ }^{1} \mathrm{H}$ NMR (300 MHz, $\mathrm{CDCl}_{3}$ ), $\delta$ (ppm): 10.70 (brs, $\left.1 \mathrm{H}\right), 8.04-7.92$ (m, 2H), 7.88$7.57(\mathrm{~m}, 6 \mathrm{H}), 7.52-7.26(\mathrm{~m}, 4 \mathrm{H}), 7.17-7.00(\mathrm{~m}, 1 \mathrm{H})$. HRMS (EI) $\mathrm{m} / z$ : calcd for $\mathrm{C}_{23} \mathrm{H}_{15} \mathrm{FN}_{4}\left[\mathrm{M}^{+}\right]$: 366.1281, found: 366.1281

4-(2-chlorophenyl)-2-(methylamino)-6-phenylpyrimidine-5-carbonitrile (19f). Yield: 75\%. Mp 198-200 C. ${ }^{1} \mathrm{H}$ NMR (300 MHz, $\left.\mathrm{CDCl}_{3}\right), \delta$ (ppm): 8.48 (s, 1H), 8.01-7.82 (m, 2H), 7.68$7.47(\mathrm{~m}, 7 \mathrm{H}), 3.00-2.86(\mathrm{~m}, 3 \mathrm{H})$. HRMS (EI) $\mathrm{m} / \mathrm{z}$ : calcd for $\mathrm{C}_{18} \mathrm{H}_{13} \mathrm{ClN}_{4}\left[\mathrm{M}^{+}\right]$: 320.0829 , found: 320.0823 .

4-(2-chlorophenyl)-6-phenyl-2-(phenylamino)pyrimidine-5-carbonitrile (19g). Yield: 52\%. Mp 119-121 ${ }^{\circ} \mathrm{C} .{ }^{1} \mathrm{H}$ NMR (300 MHz, $\left.\mathrm{CDCl}_{3}\right), \delta(\mathrm{ppm}): 8.13-8.05$ (m, 2H), $7.70(\mathrm{~d}, J=8.0 \mathrm{~Hz}$, 2H), 7.65-7.50 (m, 6H), 7.52-7.40 (m, 2H), $7.37(\mathrm{dd}, J=7.8 \mathrm{~Hz}, 2 \mathrm{H}), 7.13(\mathrm{dd}, J=7.4 \mathrm{~Hz}, 1 \mathrm{H}) . \mathrm{MS}$ (EI) $m / z: 383.0\left(\mathrm{M}^{+}, 48\right), 382.0\left(\mathrm{M}^{+}, 65\right), 381.0\left(\mathrm{M}^{+}, 100\right), 172.0(39)$.

4-(2-methoxyphenyl)-2-(methylamino)-6-phenylpyrimidine-5-carbonitrile (19h). Yield: 39\%. Mp 229-230 ${ }^{\circ}$. ${ }^{1} \mathrm{H}$ NMR (300 MHz, DMSO- $d 6$ ), $\delta(\mathrm{ppm}): 8.32-8.30$ (m, $\left.1 \mathrm{H}\right), 7.94-7.90(\mathrm{~m}, 1 \mathrm{H})$, 7.85-7.81 (m, 1H), 7.57-7.35 (m, 5H), 7.28 (d, $J=4.1 \mathrm{~Hz}, 1 \mathrm{H}), 7.20-7.04(\mathrm{~m}, 1 \mathrm{H}), 3.81(\mathrm{~s}, 3 \mathrm{H}), 2.95$ $(\mathrm{d}, J=4.7 \mathrm{~Hz}, 3 \mathrm{H}) .{ }^{13} \mathrm{C}$ NMR $\left(75 \mathrm{MHz}, \mathrm{DMSO}-d_{6}\right) \delta(\mathrm{ppm}): 171.2,168.7,162.0,156.6,136.7,131.8$, 31.1, 130.2, 129.9, 128.8, 126.1, 120.6, 118.1, 111.9, 93.3, 55.7, 28.1. HRMS (ESI) $m / z$ : calcd for $\mathrm{C}_{19} \mathrm{H}_{16} \mathrm{~N}_{4} \mathrm{O}[\mathrm{M}+\mathrm{H}]^{+}:$317.1402, found: 317.1397.

4-(2-methoxyphenyl)-6-phenyl-2-(phenylamino)pyrimidine-5-carbonitrile (19i). Yield: 47\%. Mp 199-201 ${ }^{\circ} \mathrm{C} .{ }^{1} \mathrm{H}$ NMR (300 MHz, DMSO-d6), $\delta(\mathrm{ppm}): 8.79-8.73$ (m, 2H), $8.34-8.28$ (m, 
2H), $8.17(\mathrm{dd}, J=8.4,1.3 \mathrm{~Hz}, 1 \mathrm{H}), 7.56-7.48(\mathrm{~m}, 2 \mathrm{H}), 7.44-7.37(\mathrm{~m}, 2 \mathrm{H}), 7.23(\mathrm{td}, J=7.5,1.3 \mathrm{~Hz}$, $1 \mathrm{H}), 7.20-7.13(\mathrm{~m}, 2 \mathrm{H}), 6.93(\mathrm{tt}, J=7.1,1.1 \mathrm{~Hz}, 1 \mathrm{H}), 6.85(\mathrm{dd}, J=7.7,1.3 \mathrm{~Hz}, 1 \mathrm{H}), 5.54$ (brs, $1 \mathrm{H})$ 3.94 (s, 3H). HRMS (EI) $m / z$ : calcd for $\mathrm{C}_{24} \mathrm{H}_{18} \mathrm{~N}_{4} \mathrm{O}\left[\mathrm{M}^{+}\right]$: 378.1481 , found: 378.1476 .

4-(3-fluorophenyl)-2-(methylamino)-6-phenylpyrimidine-5-carbonitrile (19j). Yield: 45\%. Mp 237-239 ${ }^{\circ}$. ${ }^{1} \mathrm{H}$ NMR (300 MHz, DMSO- $\left.d_{6}\right), \delta(\mathrm{ppm}): 8.32-8.26(\mathrm{~m}, 2 \mathrm{H}), 8.18-8.12(\mathrm{~m}$, $1 \mathrm{H}), 8.06(\mathrm{~s}, 1 \mathrm{H}), 7.74(\mathrm{dd}, J=8.6,7.8 \mathrm{~Hz}, 1 \mathrm{H}), 7.56-7.48(\mathrm{~m}, 2 \mathrm{H}), 7.44-7.37(\mathrm{~m}, 1 \mathrm{H}), 7.06-7.00$ (m, 1H), 5.56 (brs, $1 \mathrm{H}), 3.30(\mathrm{~d}, J=2.7 \mathrm{~Hz}, 3 \mathrm{H})$. HRMS (EI) $m / z$ : calcd for $\mathrm{C}_{18} \mathrm{H}_{13} \mathrm{FN}_{4}\left[\mathrm{M}^{+}\right]: 304.1124$, found: 304.1112 .

4-(3-fluorophenyl)-6-phenyl-2-(phenylamino)pyrimidine-5-carbonitrile (19k). Yield: 44\%. Mp 176-177 ${ }^{\circ} \mathrm{C} .{ }^{1} \mathrm{H}$ NMR (300 MHz, DMSO-d6), $\delta(\mathrm{ppm}): 10.66$ (s, 1H), 8.01-7.93 (m, 2H), 7.87-7.74 (m, 4H), 7.71-7.57 (m, 4H), 7.56-7.42 (m, 1H), $7.35(\mathrm{dd}, J=7.9 \mathrm{~Hz}, 2 \mathrm{H}), 7.07$ (dd, $J=7.4$ $\mathrm{Hz}, 1 \mathrm{H})$. HRMS (EI) $m / z$ : calcd for $\mathrm{C}_{23} \mathrm{H}_{15} \mathrm{FN}_{4}\left[\mathrm{M}^{+}\right]$: 366.1281, found: 366.1266 .

4-(3-chlorophenyl)-2-(methylamino)-6-phenylpyrimidine-5-carbonitrile (19l). Yield: 69\%. Mp 214-215 ${ }^{\circ} \mathrm{C} .{ }^{1} \mathrm{H}$ NMR (300 MHz, $\left.\mathrm{CDCl}_{3}\right), \delta(\mathrm{ppm}): 8.89-7.70$ (m, 4H), 7.89-7.35 (m, 5H), 5.76 (brs, $1 \mathrm{H}), 3.16(\mathrm{~d}, J=5.1 \mathrm{~Hz}, 3 \mathrm{H})$. $\mathrm{HRMS}(\mathrm{EI}) \mathrm{m} / z$ : calcd for $\mathrm{C}_{18} \mathrm{H}_{13} \mathrm{ClN}_{4}\left[\mathrm{M}^{+}\right]: 320.0829$, found: 320.0824 .

4-(3-chlorophenyl)-2-(ethylamino)-6-phenylpyrimidine-5-carbonitrile (19m). Yield: $46 \%$. Mp 179-180 C. ${ }^{1} \mathrm{H}$ NMR (300 MHz, $\left.\mathrm{CDCl}_{3}\right), \delta$ (ppm): 9.14-8.99 (m, 1H), 8.82-8.66 (m, 1H), 8.57 (dd, $J=6.1 \mathrm{~Hz}, 1 \mathrm{H}), 8.41-8.20(\mathrm{~m}, 1 \mathrm{H}), 7.99-7.82(\mathrm{~m}, 2 \mathrm{H}), 7.71-7.51(\mathrm{~m}, 4 \mathrm{H}), 3.53-3.37(\mathrm{~m}, 2 \mathrm{H}), 1.18(\mathrm{t}$, $J=7.1 \mathrm{~Hz}, 3 \mathrm{H}$ ). HRMS (EI) $m / z$ : calcd for $\mathrm{C}_{19} \mathrm{H}_{15} \mathrm{ClN}_{4}$ : 334.0985 , found: 334.0823 .

4-(3-chlorophenyl)-6-phenyl-2-(phenylamino)pyrimidine-5-carbonitrile (19n). Yield: 43\%. Mp 214-215 ${ }^{\circ} \mathrm{C} .{ }^{1} \mathrm{H}$ NMR (300 MHz, $\left.\mathrm{CDCl}_{3}\right), \delta$ (ppm): 8.07-7.91 (m, 3H), 7.70 (d, $J=7.7 \mathrm{~Hz}$, 2H), 7.64-7.45 (m, 7H), $7.40(\mathrm{dd}, J=8.0 \mathrm{~Hz}, 2 \mathrm{H}), 7.15(\mathrm{dd}, J=7.8 \mathrm{~Hz}, 1 \mathrm{H})$. HRMS (EI) $m / z$ : calcd for $\mathrm{C}_{23} \mathrm{H}_{15} \mathrm{ClN}_{4}\left[\mathrm{M}^{+}\right]$: 382.0985, found: 382.1006.

4-(3-hydroxyphenyl)-2-(methylamino)-6-phenylpyrimidine-5-carbonitrile (19o). Yield: 51\%. Mp 256-258 ${ }^{\circ} \mathrm{C} .{ }^{1} \mathrm{H}$ NMR (300 MHz, DMSO-d6), $\delta$ (ppm): 9.80 (s, 1H), 8.36-8.26 (m, 1H), 7.94 $(\mathrm{dd}, J=7.5,2.1 \mathrm{~Hz}, 1 \mathrm{H}), 7.85(\mathrm{dd}, J=7.5,2.1 \mathrm{~Hz}, 1 \mathrm{H}), 7.59-7.51(\mathrm{~m}, 3 \mathrm{H}), 7.38-7.22(\mathrm{~m}, 3 \mathrm{H}), 7.02-$ $6.93(\mathrm{~m}, 1 \mathrm{H}), 2.96(\mathrm{~d}, J=4.7 \mathrm{~Hz}, 3 \mathrm{H})$. $\mathrm{HRMS}(\mathrm{EI}) \mathrm{m} / z$ : calcd for $\mathrm{C}_{18} \mathrm{H}_{14} \mathrm{~N}_{4} \mathrm{O}\left[\mathrm{M}^{+}\right]: 302.1168$, found 302.1167.

4-(3-hydroxyphenyl)-6-phenyl-2-(phenylamino)pyrimidine-5-carbonitrile (19p). Yield: 54\%. Mp 205-207 ${ }^{\circ} \mathrm{C} .{ }^{1} \mathrm{H}$ NMR (300 MHz, DMSO- $\left.d 6\right), \delta(\mathrm{ppm}): 10.60(\mathrm{dd}, 6.2 \mathrm{~Hz}, 1 \mathrm{H}), 9.88(\mathrm{dd}, J=$ $5.8 \mathrm{~Hz}, 1 \mathrm{H}), 8.08-7.72(\mathrm{~m}, 4 \mathrm{H}), 7.73-7.22(\mathrm{~m}, 8 \mathrm{H}), 7.18-6.92(\mathrm{~m}, 2 \mathrm{H})$. HRMS (EI) $\mathrm{m} / \mathrm{z}$ : calcd for $\mathrm{C}_{23} \mathrm{H}_{16} \mathrm{~N}_{4} \mathrm{O}\left[\mathrm{M}^{+}\right]: 364.1324$, found: 364.1309 . 
4-(3-methoxyphenyl)-2-(methylamino)-6-phenylpyrimidine-5-carbonitrile (19q). Yield: 58\%. Mp 197-198 ${ }^{\circ}$. ${ }^{1} \mathrm{H}$ NMR (300 MHz, DMSO- $d 6$ ), $\delta$ (ppm): 8.38 (d, $J=4.5 \mathrm{~Hz}, 1 \mathrm{H}$ ), 8.00-7.81 $(\mathrm{m}, 2 \mathrm{H}), 7.65-7.39(\mathrm{~m}, 6 \mathrm{H}), 7.26-7.08(\mathrm{~m}, 1 \mathrm{H}), 3.84(\mathrm{~s}, 3 \mathrm{H}), 2.96(\mathrm{~d}, J=4.6 \mathrm{~Hz}, 3 \mathrm{H})$. HRMS (EI) $\mathrm{m} / \mathrm{z}$ : calcd for $\mathrm{C}_{19} \mathrm{H}_{16} \mathrm{~N}_{4} \mathrm{O}\left[\mathrm{M}^{+}\right]$: 316.1324 , found: 316.1336 .

4-(3-methoxyphenyl)-6-phenyl-2-(phenylamino)pyrimidine-5-carbonitrile (19r). Yield: 67\%. Mp 135-137 ${ }^{\circ} \mathrm{C} .{ }^{1} \mathrm{H}$ NMR (300 MHz, DMSO- $d 6$ ), $\delta$ (ppm): 10.62 (s, 1H), 8.04-7.92 (m, 2H), 7.83 $(\mathrm{d}, J=8.5 \mathrm{~Hz}, 2 \mathrm{H}), 7.67-7.48(\mathrm{~m}, 6 \mathrm{H}), 7.36(\mathrm{t}, J=7.8 \mathrm{~Hz}, 2 \mathrm{H}), 7.23-7.15(\mathrm{~m}, 1 \mathrm{H}), 7.07(\mathrm{dd}, J=7.8$, 1H), 3.85 (s, 3H). HRMS (EI) $m / z$ : calcd for $\mathrm{C}_{24} \mathrm{H}_{18} \mathrm{~N}_{4} \mathrm{O}\left[\mathrm{M}^{+}\right]$: 378.1481, found: 378.1490 .

4-(3-cyanophenyl)-2-(methylamino)-6-phenylpyrimidine-5-carbonitrile (19s). Yield: 43\%. Mp 247-248 ${ }^{\circ} \mathrm{C} .{ }^{1} \mathrm{H}$ NMR (300 MHz, DMSO- $\left.d 6\right), \delta(\mathrm{ppm}): 8.55-8.41(\mathrm{~m}, 1 \mathrm{H}), 8.42-8.13(\mathrm{~m}, 2 \mathrm{H}), 8.12-$ $8.02(\mathrm{~m}, 1 \mathrm{H}), 7.96(\mathrm{dd}, J=7.5,2.1 \mathrm{~Hz}, 1 \mathrm{H}), 7.87(\mathrm{dd}, J=7.5,2.1 \mathrm{~Hz}, 1 \mathrm{H}), 7.82-7.76(\mathrm{~m}, J=7.9,2.7$ $\mathrm{Hz}, 1 \mathrm{H}), 7.64-7.50(\mathrm{~m}, 3 \mathrm{H}), 2.96(\mathrm{~d}, J=4.7 \mathrm{~Hz}, 3 \mathrm{H}) .{ }^{13} \mathrm{C}$ NMR $\left(75 \mathrm{MHz}, \mathrm{DMSO}-d_{6}\right) \delta(\mathrm{ppm}): 170.5$, 169.3, 162.2, 138.3, 137.2, 135.1, 134.2, 134.1, 133.2, 131.8, 130.5, 129.5, 129.2, 119.0, 112.2, 91.4, 28.6. HRMS (EI) $m / z$ : calcd for $\mathrm{C}_{19} \mathrm{H}_{13} \mathrm{~N}_{5}\left[\mathrm{M}^{+}\right]$: 311.3400 , found: 311.3394 .

4-(3-cyanophenyl)-2-(ethylamino)-6-phenylpyrimidine-5-carbonitrile (19t). Yield: 40\%. Mp 175-176 ${ }^{\circ} \mathrm{C} .{ }^{1} \mathrm{H}$ NMR (300 MHz, $\left.\mathrm{CDCl}_{3}\right), \delta(\mathrm{ppm}): 8.58(\mathrm{~s}, 1 \mathrm{H}), 8.34(\mathrm{dd}, J=15.8,1.0 \mathrm{~Hz}, 1 \mathrm{H})$, $8.21(\mathrm{dd}, J=15.8,7.2 \mathrm{~Hz}, 1 \mathrm{H}), 8.07(\mathrm{~d}, J=7.2 \mathrm{~Hz}, 1 \mathrm{H}), 7.91(\mathrm{dd} J=18.6,6.9 \mathrm{~Hz}, 2 \mathrm{H}), 7.86-7.72$ $(\mathrm{m}, 1 \mathrm{H}), 7.69-7.51(\mathrm{~m}, 3 \mathrm{H}), 3.52-3.39(\mathrm{~m}, 2 \mathrm{H}), 1.17(\mathrm{t}, J=7.1 \mathrm{~Hz}, 3 \mathrm{H}) .{ }^{13} \mathrm{C}$ NMR $(75 \mathrm{MHz}, \mathrm{DMSO}-$ d6) $\delta$ (ppm): 170.9, 169.2, 161.5, 138.3, 137.2, 135.1, 134.2, 134.1, 133.2, 131.8, 130.5, 129.5, 129.1, 119.0, 112.2, 91.5, 36.5, 15.0. HRMS (EI) $m / z$ : calcd for $\mathrm{C}_{20} \mathrm{H}_{15} \mathrm{~N}_{5}: 325.1327$ found: 325.1328 .

4-(3-cyanophenyl)-6-phenyl-2-(phenylamino)pyrimidine-5-carbonitrile $\quad(19 u)$ Yield: 46\%. Mp 211-212 ${ }^{\circ} \mathrm{C} .{ }^{1} \mathrm{H}$ NMR (300 MHz, DMSO- $\left.d 6\right), \delta(\mathrm{ppm}): 10.70$ (s, 1H), $8.41(\mathrm{~s}, 1 \mathrm{H}), 8.33-8.21$ $(\mathrm{m}, 1 \mathrm{H}), 8.16-8.05(\mathrm{~m}, 1 \mathrm{H}), 8.04-7.93(\mathrm{~m}, 2 \mathrm{H}), 7.90-7.73(\mathrm{~m}, 3 \mathrm{H}), 7.68-7.57(\mathrm{~m}, 3 \mathrm{H}), 7.35(\mathrm{dd}, J=$ $7.9 \mathrm{~Hz}, 2 \mathrm{H}), 7.07$ (dd, $J=7.3 \mathrm{~Hz}, 1 \mathrm{H})$. $\mathrm{HRMS}(\mathrm{EI}) \mathrm{m} / z$ : calcd for: $\mathrm{C}_{24} \mathrm{H}_{15} \mathrm{~N}_{5}\left[\mathrm{M}^{+}\right]$: 373.1327 , found: 373.1325 .

4-(4-fluorophenyl)-2-(methylamino)-6-phenylpyrimidine-5-carbonitrile (19v). Yield: 47\%. Mp 250-251 ${ }^{\circ} \mathrm{C} .{ }^{1} \mathrm{H}$ NMR (300 MHz, $\left.\mathrm{CDCl}_{3}\right), \delta(\mathrm{ppm}):$ 7.95-7.67 (m, 4H), 7.42-7.36 (m, 3H), $7.04(\mathrm{t}, J=8.6 \mathrm{~Hz}, 2 \mathrm{H}), 5.65(\mathrm{bs}, 1 \mathrm{H}), 2.96(\mathrm{t}, J=4.3 \mathrm{~Hz}, 3 \mathrm{H})$. HRMS (EI) $m / z$ : calcd for $\mathrm{C}_{18} \mathrm{H}_{13} \mathrm{FN}_{4}$ $\left[\mathrm{M}^{+}\right]:$304.1124, found: 304.1122.

4-(4-fluorophenyl)-6-phenyl-2-(phenylamino)pyrimidine-5-carbonitrile (19w). Yield: 65\%. Mp 188-190 C. ${ }^{1} \mathrm{H}$ NMR (300 MHz, $\left.\mathrm{CDCl}_{3}\right), \delta(\mathrm{ppm}): 8.09-8.00(\mathrm{~m}, 4 \mathrm{H}), 7.79-7.55(\mathrm{~m}, 6 \mathrm{H})$, $7.38(\mathrm{t}, J=7.91 \mathrm{~Hz}, 2 \mathrm{H}), 7.27-7.20(\mathrm{~m}, 2 \mathrm{H}), 7.14(\mathrm{t}, J=7.41 \mathrm{~Hz}, 1 \mathrm{H})$. HRMS (EI) $\mathrm{m} / z$ : calcd for $\mathrm{C}_{23} \mathrm{H}_{15} \mathrm{FN}_{4}\left[\mathrm{M}^{+}\right]:$366.1281, found: 366.1291 . 
4-(4-bromophenyl)-2-(methylamino)-6-phenylpyrimidine-5-carbonitrile (19x). Yield: 56\%. Mp 230-231 ${ }^{\circ} \mathrm{C} .{ }^{1} \mathrm{H}$ NMR (300 MHz, $\left.\mathrm{CDCl}_{3}\right), \delta(\mathrm{ppm}): 8.17-7.73(\mathrm{~m}, 4 \mathrm{H}), 7.76-7.42(\mathrm{~m}, 5 \mathrm{H})$, 5.76 (brs, 1H), 3.14 (s, 3H). MS (EI) m/z: $366.2\left([\mathrm{M}+\mathrm{H}]^{+}, 99\right), 365.2\left(\mathrm{M}^{+}, 85\right), 364.2\left([\mathrm{M}+\mathrm{H}]^{+}, 100\right)$, $363.2\left(\mathrm{M}^{+}, 67\right), 285.2(61), 256.1(43)$.

4-(4-bromophenyl)-6-phenyl-2-(phenylamino)pyrimidine-5-carbonitrile (19y). Yield: 44\%. Mp 205-207 C. ${ }^{1} \mathrm{H}$ NMR (300 MHz, $\left.\mathrm{CDCl}_{3}\right), \delta(\mathrm{ppm}): 8.07-7.88$ (m, 4H), 7.76-7.64 (m, 4H), 7.65-7.52 (m, 3H), 7.43-7.34 (m, 2H), 7.22-7.11 (m, 1H). MS (EI) m/z: $428.1\left([\mathrm{M}+\mathrm{H}]^{+}, 99\right), 427.0$ $\left(\mathrm{M}^{+}, 85\right), 426.0\left([\mathrm{M}+\mathrm{H}]^{+}, 100\right), 425.0\left(\mathrm{M}^{+}, 67\right), 347.0(17), 172.0$ (15).

4-(4-hydroxyphenyl)-2-(methylamino)-6-phenylpyrimidine-5-carbonitrile (19z). Yield: 75\%. Mp 307-308 ${ }^{\circ} \mathrm{C} .{ }^{1} \mathrm{H}$ NMR (300 MHz, DMSO- $d 6$ ), $\delta$ (ppm): 10.15 (bs, $\left.1 \mathrm{H}\right), 8.23$ (bs, 1H), $7.92-$ $7.78(\mathrm{~m}, 4 \mathrm{H}), 7.56-7.52(\mathrm{~m}, 3 \mathrm{H}), 6.93-6.88(\mathrm{~m}, 2 \mathrm{H}), 2.95(\mathrm{~d}, J=3.8 \mathrm{~Hz}, 3 \mathrm{H}){ }^{13} \mathrm{C}$ NMR $(75 \mathrm{MHz}$, $\left.\mathrm{CDCl}_{3}\right) \delta(\mathrm{ppm}): 170.3,169.6,161.5,160.5,137.0,130.9,129.0,128.4,127.4,127.1,119.3,115.2$, 89.8, 28.0. HRMS (ESI) $m / z$ : calcd for $\mathrm{C}_{18} \mathrm{H}_{14} \mathrm{~N}_{4} \mathrm{O}[\mathrm{M}+\mathrm{H}]^{+}:$303.1246, found: 303.1240 .

4-(4-hydroxyphenyl)-6-phenyl-2-(phenylamino)pyrimidine-5-carbonitrile (19aa). Yield: $52 \%$. Mp 286-287 ${ }^{\circ} \mathrm{C} .{ }^{1} \mathrm{H}$ NMR (300 MHz, DMSO- $d 6$ ), $\delta$ (ppm): 10.51 (brs, 1H), 10.24 (s, 1H), 7.96$7.90(\mathrm{~m}, 4 \mathrm{H}), 7.83-7.80(\mathrm{~d}, J=7.6 \mathrm{~Hz}, 2 \mathrm{H}), 7.60-7.57(\mathrm{~m}, 3 \mathrm{H}), 7.34(\mathrm{~m}, 2 \mathrm{H}), 7.04-7.01(\mathrm{~m}, 1 \mathrm{H}), 6.95$ $(\mathrm{d}, J=7.6 \mathrm{~Hz}, 2 \mathrm{H}) .{ }^{13} \mathrm{C} \mathrm{NMR}\left(75 \mathrm{MHz}, \mathrm{CDCl}_{3}\right) \delta(\mathrm{ppm}): 170.7,169.7,160.6,159.0,139.3,136.6$, 131.1, 129.1, 129.0, 128.8, 128.6, 126.9, 123.2, 120.4, 118.8, 115.4, 92.2. HRMS (ESI) $m / z$ : calcd for: $\mathrm{C}_{23} \mathrm{H}_{16} \mathrm{~N}_{4} \mathrm{O}[\mathrm{M}+\mathrm{H}]^{+}:$365.1402, found: 365,1397 .

4-(4-methoxyphenyl)-2-(methylamino)-6-phenylpyrimidine-5-carbonitrile (19ab). Yield: 73\%. Mp 196-198 ${ }^{\circ} \mathrm{C} .{ }^{1} \mathrm{H}$ NMR (300 MHz, $\left.\mathrm{CDCl}_{3}\right), \delta(\mathrm{ppm}): 8.21-7.57$ (m, 4H), 7.52-7.23 (m, 3H), 6.99-6.74 (m, 2H), 5.54 (brs, 1H), $3.72(\mathrm{~s}, 3 \mathrm{H}), 2.98$ (d, $J=4.7 \mathrm{~Hz}, 3 \mathrm{H})$. HRMS (EI) $\mathrm{m} / z$ : calcd for $\mathrm{C}_{19} \mathrm{H}_{16} \mathrm{~N}_{4} \mathrm{O}[\mathrm{M}]^{+}:$316.1324, found: 316.1323 .

4-(4-methoxyphenyl)-6-phenyl-2-(phenylamino)pyrimidine-5-carbonitrile (19ac). Yield: 60\%. Mp 175-177 ${ }^{\circ} \mathrm{C} .{ }^{1} \mathrm{H}$ NMR (300 MHz, $\left.\mathrm{CDCl}_{3}\right), \delta(\mathrm{ppm}): 8.16-8.03$ (m, 2H), 8.07-7.95 (m, 2H), 7.77-7.67 (m, 2H), 7.61-7.51 (m, 4H), 7.39 (dd, $J=7.9 \mathrm{~Hz}, 2 \mathrm{H}), 7.18-7.02(\mathrm{~m}, 3 \mathrm{H}), 3.90$ (s, 3H). HRMS (EI) $m / z$ : calcd for $\mathrm{C}_{24} \mathrm{H}_{18} \mathrm{~N}_{4} \mathrm{O}[\mathrm{M}]^{+}: 378.1481$, found: 378.1487 .

2-(methylamino)-4-phenyl-6-(p-tolyl)pyrimidine-5-carbonitrile (19ad). Yield: $63 \%$. Mp 191-192 ${ }^{\circ} \mathrm{C} .{ }^{1} \mathrm{H}$ NMR (300 MHz, $\left.\mathrm{CDCl}_{3}\right), \delta(\mathrm{ppm}): 8.30-7.67$ (m, 4H), 7.66-7.41 (m, 3H), 7.33 (d, $J=$ $7.9 \mathrm{~Hz}, 2 \mathrm{H}), 5.78$ (brs, $1 \mathrm{H}), 3.12(\mathrm{~d}, J=4.9 \mathrm{~Hz}, 3 \mathrm{H}), 2.44$ (s, 3H). HRMS (EI) $m / z$ : calcd for $\mathrm{C}_{19} \mathrm{H}_{16} \mathrm{~N}_{4}$ $[\mathrm{M}]^{+}:$300.1375, found: 300.1380 .

4-phenyl-2-(phenylamino)-6-(p-tolyl)pyrimidine-5-carbonitrile (19ae). Yield: $74 \%$. Mp 147-149 ${ }^{\circ} \mathrm{C} .{ }^{1} \mathrm{H}$ NMR (300 MHz, DMSO- $\left.d_{6}\right), \delta(\mathrm{ppm}): 10.54(\mathrm{~s}, 1 \mathrm{H}), 8.01-7.92(\mathrm{~m}, 2 \mathrm{H}), 7.88(\mathrm{~d}, J=$ $8.1 \mathrm{~Hz}, 2 \mathrm{H}), 7.81(\mathrm{dd}, J=7.8,0.9 \mathrm{~Hz}, 2 \mathrm{H}), 7.68-7.52(\mathrm{~m}, 3 \mathrm{H}), 7.40(\mathrm{~d}, J=7.9 \mathrm{~Hz}, 2 \mathrm{H}), 7.33(\mathrm{dd}, J$ 
$=7.1 \mathrm{~Hz}, 2 \mathrm{H}), 7.05(\mathrm{td}, J=7.2,1.1 \mathrm{~Hz}, 1 \mathrm{H}), 2.40(\mathrm{~s}, 3 \mathrm{H})$. HRMS (EI) $m / z$ : calcd for $\mathrm{C}_{24} \mathrm{H}_{18} \mathrm{~N}_{4}[\mathrm{M}]^{+}$: 362.1530, found: 362.1520 .

4-(2,4-difluorophenyl)-2-(methylamino)-6-phenylpyrimidine-5-carbonitrile (19af). Yield: 54\%. Mp 221-223 ${ }^{\circ} \mathrm{C} .{ }^{1} \mathrm{H}$ NMR (300 MHz, $\left.\mathrm{CDCl}_{3}\right), \delta(\mathrm{ppm}): 8.06(\mathrm{~d}, J=5.6 \mathrm{~Hz}, 1 \mathrm{H}), 7.93(\mathrm{~d}, J=6.1$ $\mathrm{Hz}, 1 \mathrm{H}), 7.75-7.45(\mathrm{~m}, 3 \mathrm{H}), 7.11-6.93(\mathrm{~m}, 3 \mathrm{H}), 5.84(\mathrm{~d}, J=22.5 \mathrm{~Hz}, 1 \mathrm{H}), 3.12(\mathrm{dd}, J=17.6,4.2 \mathrm{~Hz}$, $3 \mathrm{H})$. HRMS (EI) $m / z$ : calcd for $\mathrm{C}_{18} \mathrm{H}_{12} \mathrm{~F}_{2} \mathrm{~N}_{4}[\mathrm{M}]^{+}: 322.1030$, found 322.1017 .

4-(2,4-difluorophenyl)-6-phenyl-2-(phenylamino)pyrimidine-5-carbonitrile (19ag). Yield: 51\%. Mp 192-194 ${ }^{\circ} .{ }^{1} \mathrm{H}$ NMR (300 MHz, $\left.\mathrm{CDCl}_{3}\right), \delta(\mathrm{ppm}):$ 7.66-7.47 (m, 2H), 7.39-7.18 (m, 6H), $7.10(\mathrm{dd}, J=7.3 \mathrm{~Hz}, 1 \mathrm{H}), 6.97(\mathrm{dd}, J=8.2 \mathrm{~Hz}, 2 \mathrm{H}), 6.85(\mathrm{~d}, J=7.6 \mathrm{~Hz}, 2 \mathrm{H}), 5.77$ (brs, $1 \mathrm{H}) . \mathrm{MS}(\mathrm{EI})$ $m / z: 384.1\left(\mathrm{M}^{+}, 75\right), 273.1(100), 269.0$ (48).

4-(3,5-difluorophenyl)-2-(methylamino)-6-phenylpyrimidine-5-carbonitrile

(19ah). Yield: $69 \%$. Mp 264-266 ${ }^{\circ} \mathrm{C} .{ }^{1} \mathrm{H}$ NMR $\left(300 \mathrm{MHz}, \mathrm{CDCl}_{3}\right), \delta(\mathrm{ppm}): 8.03$ (d, $\left.J=6.4 \mathrm{~Hz}, 1 \mathrm{H}\right), 7.90$ (d, $J=5.8 \mathrm{~Hz}, 1 \mathrm{H}), 7.62-7.41(\mathrm{~m}, 5 \mathrm{H}), 7.05-6.94(\mathrm{~m}, 1 \mathrm{H}), 7.82-7.77(\mathrm{~m}, 1 \mathrm{H}), 3.16(\mathrm{~d}, J=5.8 \mathrm{~Hz}, 3 \mathrm{H})$. HRMS (EI) $m / z$ : calcd for $\mathrm{C}_{18} \mathrm{H}_{12} \mathrm{~F}_{2} \mathrm{~N}_{4}[\mathrm{M}]^{+}:$322.1030, found: 322.1032 .

4-(3,5-difluorophenyl)-6-phenyl-2-(phenylamino)pyrimidine-5-carbonitrile (19ai). Yield: 45\%. Mp 264-264 $\mathrm{C} .{ }^{1} \mathrm{H}$ NMR (300 MHz, $\left.\mathrm{CDCl}_{3}\right), \delta(\mathrm{ppm}): 8.02(\mathrm{~d}, J=4.6 \mathrm{~Hz}, 2 \mathrm{H}), 7.81-7.51(\mathrm{~m}$, $8 \mathrm{H}), 7.40(\mathrm{dd}, J=7.5 \mathrm{~Hz}, 2 \mathrm{H}), 7.16(\mathrm{dd}, J=7.5 \mathrm{~Hz}, 1 \mathrm{H}), 7.03(\mathrm{t}, J=8.0 \mathrm{~Hz}, 1 \mathrm{H})$. HRMS (EI) $m / z$ : calcd for $\mathrm{C}_{23} \mathrm{H}_{14} \mathrm{~F}_{2} \mathrm{~N}_{4}[\mathrm{M}]^{+}:$384.1187, found: 384.1191 .

4-(3,5-dichlorophenyl)-2-(methylamino)-6-phenylpyrimidine-5-carbonitrile (19aj). Yield: 62\%. Mp 245-246 ${ }^{\circ} \mathrm{C} .{ }^{1} \mathrm{H}$ NMR (300 MHz, $\left.\mathrm{CDCl}_{3}\right), \delta$ (ppm): 8.03 (d, $\left.J=6.9 \mathrm{~Hz}, 1 \mathrm{H}\right), 7.94-7.85$ (m, 2H), $7.79(\mathrm{~s}, 1 \mathrm{H}), 7.63-7.44(\mathrm{~m}, 4 \mathrm{H}), 5.91-5.68(\mathrm{~m}, 1 \mathrm{H}), 3.15(\mathrm{~d}, J=5.7 \mathrm{~Hz}, 3 \mathrm{H}) . \mathrm{HRMS}(\mathrm{EI}) \mathrm{m} / z$ : calcd for $\mathrm{C}_{18} \mathrm{H}_{12} \mathrm{Cl}_{2} \mathrm{~N}_{4}$ : 354.0439, found: 354.0427 .

4-(3,5-dichlorophenyl)-2-(ethylamino)-6-phenylpyrimidine-5-carbonitrile (19ak). Yield: 54\%. Mp 192-193ㄷ. ${ }^{1} \mathrm{H}$ NMR (300 MHz, DMSO- $d_{6}$ ), $\delta$ (ppm): 10.42 (brs, 1H), 8.32 - 8.26 (m, 2H), $8.20(\mathrm{~s}, 2 \mathrm{H}), 7.56-7.48(\mathrm{~m}, 2 \mathrm{H}), 7.44-7.37(\mathrm{~m}, 1 \mathrm{H}), 7.35(\mathrm{t}, J=2.2 \mathrm{~Hz}, 1 \mathrm{H}), 3.46(\mathrm{q}, J=7.6 \mathrm{~Hz}$, 2H), $1.25-1.19$ (m, 3H). MS (EI) m/z: 372.0 (33), 370.0 (60), $368.0\left(\mathrm{M}^{+}, 100\right), 352.7$ (57).

4-(3,5-dichlorophenyl)-6-phenyl-2-(phenylamino)pyrimidine-5-carbonitrile (19l). Yield: 55\%. Mp 179-181 ${ }^{\circ} \mathrm{C} .{ }^{1} \mathrm{H}$ NMR (300 MHz, $\left.\mathrm{CDCl}_{3}\right), \delta$ (ppm): 7.95-7.79 (m, 2H), 7.72 (d, J = 1.9 Hz, $2 \mathrm{H}), 7.52(\mathrm{~d}, J=7.8 \mathrm{~Hz}, 2 \mathrm{H}), 7.43-7.34(\mathrm{~m}, 4 \mathrm{H}), 7.24(\mathrm{dd}, J=7.8 \mathrm{~Hz}, 2 \mathrm{H}), 7.01(\mathrm{dd}, J=7.4 \mathrm{~Hz}, 1 \mathrm{H})$. MS (EI) m/z: 420.0 (31), 416.9 (97), $416.0\left(\mathrm{M}^{+}, 100\right), 414.9$ (95), 381.0 (56), 208.0 (49).

4-(3,5-dimethoxyphenyl)-2-(methylamino)-6-phenylpyrimidine-5-carbonitrile (19am). Yield: $64 \%$. Mp 207-209 ${ }^{\circ} \mathrm{C} .{ }^{1} \mathrm{H}$ NMR (300 MHz, DMSO-d6), $\delta$ (ppm): 8.58-8.21 (m, 1H), 7.93 (d, $J$ $=6.9 \mathrm{~Hz}, 1 \mathrm{H}), 7.84(\mathrm{~d}, J=6.9 \mathrm{~Hz}, 1 \mathrm{H}), 7.76-7.41(\mathrm{~m}, 3 \mathrm{H}), 7.07(\mathrm{~d}, J=2.2 \mathrm{~Hz}, 1 \mathrm{H}), 6.98(\mathrm{~d}, J=2.1$ 
$\mathrm{Hz}, 1 \mathrm{H}), 6.79-6.61(\mathrm{~m}, 1 \mathrm{H}), 3.80(\mathrm{~s}, 3 \mathrm{H}), 3.79(\mathrm{~s}, 3 \mathrm{H}), 2.94(\mathrm{~d}, J=4.7 \mathrm{~Hz}, 3 \mathrm{H}) . \mathrm{HRMS}(\mathrm{EI}) \mathrm{m} / z$ : calcd for $\mathrm{C}_{20} \mathrm{H}_{18} \mathrm{~N}_{4} \mathrm{O}_{2}[\mathrm{M}]^{+}:$346.1430, found: 346.1416.

4-(3,5-dimethoxyphenyl)-6-phenyl-2-(phenylamino)pyrimidine-5-carbonitrile (19an). Yield: 59\%. Mp 196-197 C. ${ }^{1} \mathrm{H}$ NMR (300 MHz, DMSO- $\left.d_{6}\right), \delta(\mathrm{ppm}): 10.61(\mathrm{~s}, 1 \mathrm{H}), 8.00-7.92$ (m, 2H), $7.81(\mathrm{~d}, J=7.6 \mathrm{~Hz}, 2 \mathrm{H}), 7.65-7.51(\mathrm{~m}, 3 \mathrm{H}), 7.34(\mathrm{dd}, J=7.9 \mathrm{~Hz}, 2 \mathrm{H}), 7.17-6.99(\mathrm{~m}, 3 \mathrm{H}), 6.74$ (t, $J=2.3 \mathrm{~Hz}, 1 \mathrm{H}$ ), 3.82 (s, 6H). HRMS (EI) $m / z$ : calcd for $\mathrm{C}_{25} \mathrm{H}_{20} \mathrm{~N}_{4} \mathrm{O}_{2}$ : 408.1586, found: 408.1594.

4-(benzo $[d][1,3]$ dioxol-5-yl)-2-(methylamino)-6-phenylpyrimidine-5-carbonitrile (19ao). Yield: 59\%. Mp 214-216 ${ }^{\circ} \mathrm{C} .{ }^{1} \mathrm{H}$ NMR (300 MHz, $\left.\mathrm{CDCl}_{3}\right), \delta(\mathrm{ppm})$ : 8.04-7.84 (m, 2H), 7.72-7.39 (m, $5 \mathrm{H}), 6.95(\mathrm{~d}, J=8.2 \mathrm{~Hz}, 1 \mathrm{H}), 6.06(\mathrm{~s}, 2 \mathrm{H}), 5.83(\mathrm{~s}, 1 \mathrm{H}), 3.11(\mathrm{~d}, J=5.1 \mathrm{~Hz}, 3 \mathrm{H}) .{ }^{13} \mathrm{C} \mathrm{NMR}(75 \mathrm{MHz}$, DMSO-d6) $\delta$ (ppm): 170.2, 169.4, 161.5, 149.9, 147.5, 136.9, 131.0, 130.3, 128.9, 128.5, 124.0, 119.0, 109.1, 109.0, 101.9, 90.1, 28.0. HRMS (EI) $m / z$ : calcd for $\mathrm{C}_{19} \mathrm{H}_{14} \mathrm{~N}_{4} \mathrm{O}_{2}[\mathrm{M}]^{+}$: 330.1117, found: 330.1117.

4-(benzo $[d][1,3]$ dioxol-5-yl)-2-(ethylamino)-6-phenylpyrimidine-5-carbonitrile (19ap). Yield: $43 \%$. Mp 189-190 $\mathrm{C} .{ }^{1} \mathrm{H}$ NMR (300 MHz, $\left.\mathrm{CDCl}_{3}\right), \delta(\mathrm{ppm}): 8.46-8.34$ (m, 1H), 7.97-7.80 (m, 2H), 7.67-7.39 (m, 5H), $7.10(\mathrm{dd}, J=8.1,3.2 \mathrm{~Hz}, 2 \mathrm{H}), 6.14(\mathrm{~d}, J=1.4 \mathrm{~Hz}, 1 \mathrm{H}), 3.56-3.37$ (m, 2H), $1.17(\mathrm{t}, J=7.1 \mathrm{~Hz}, 3 \mathrm{H}) .{ }^{13} \mathrm{C} \mathrm{NMR}\left(75 \mathrm{MHz}, \mathrm{DMSO}-d_{6}\right) \delta(\mathrm{ppm}): 171.1,169.8,161.5,150.5,148.1$, 137.2, 131.4 130.9, 129.6, 129.1, 124.4, 119.6, 109.6, 108.8, 102.5, 90.6, 36.4, 15.1. HRMS (EI) $m / z$ : calcd for $\mathrm{C}_{20} \mathrm{H}_{16} \mathrm{~N}_{4} \mathrm{O}_{2}$ : 344.1273, found: 344.1284.

4-(benzo[ $[d][1,3]$ dioxol-5-yl)-6-phenyl-2-(phenylamino)pyrimidine-5-carbonitrile (19aq). Yield: 59\%. Mp 190-192 ${ }^{\circ} \mathrm{C} .{ }^{1} \mathrm{H}$ NMR (300 MHz, $\left.\mathrm{CDCl}_{3}\right), \delta(\mathrm{ppm}): 8.01-7.99$ (m, 2H), 7.71-7.69 (m, $3 \mathrm{H}), 7.57-7.52(\mathrm{~m}, 5 \mathrm{H}), 7.39(\mathrm{dd}, J=7.84,2 \mathrm{H}), 7.13(\mathrm{dd}, J=7.41,1 \mathrm{H}), 6.97(\mathrm{~d}, J=8.17,1 \mathrm{H}), 6.08(\mathrm{~s}$, 2H). ${ }^{13} \mathrm{C}$ NMR (75 MHz, $\left.\mathrm{CDCl}_{3}\right) \delta$ (ppm): 171.2. 170.0, 158.8, 150.3, 147.9, 138.0, 101.6, 93.2. HRMS (EI) $m / z$ : calcd for $\mathrm{C}_{24} \mathrm{H}_{16} \mathrm{~N}_{4} \mathrm{O}_{2}[\mathrm{M}]^{+}:$392.1273, found 392.1270.

2-(methylamino)-4-phenyl-6-(3,4,5-trimethoxyphenyl)pyrimidine-5-carbonitrile (19ar). Yield: 49\%. Mp 197-199 ${ }^{\circ} \mathrm{C} .{ }^{1} \mathrm{H}$ NMR (300 MHz, $\left.\mathrm{CDCl}_{3}\right), \delta$ (ppm): 8.07-7.97 (m, 1H), 7.94-7.83 (m, 1H), 7.61-7.48 (m, 3H), $7.34(\mathrm{~s}, 1 \mathrm{H}), 7.24-7.14(\mathrm{~m}, 1 \mathrm{H}), 5.94(\mathrm{~s}, 1 \mathrm{H}), 3.78(\mathrm{~s}, 6 \mathrm{H}), 3.75(\mathrm{~s}, 3 \mathrm{H}), 3.23-$ $2.92(\mathrm{~m}, 3 \mathrm{H})$. HRMS (EI) $m / z$ : calcd for $\mathrm{C}_{21} \mathrm{H}_{20} \mathrm{~N}_{4} \mathrm{O}_{3}[\mathrm{M}]^{+}: 376.1535$, found: 376.1543 .

4-phenyl-2-(phenylamino)-6-(3,4,5-trimethoxyphenyl)pyrimidine-5-carbonitrile (19as). Yield: 68\%. Mp 192-194 $\mathrm{C} .{ }^{1} \mathrm{H}$ NMR $\left(300 \mathrm{MHz}, \mathrm{CDCl}_{3}\right), \delta(\mathrm{ppm})$ : 8.05-7.98 (m, 2H), 7.77-7.69 (m, 2H), $7.64(\mathrm{~s}, 1 \mathrm{H}), 7.60-7.52(\mathrm{~m}, 3 \mathrm{H}), 7.45-7.40(\mathrm{~m}, 4 \mathrm{H}), 7.14(\mathrm{dd}, J=7.4 \mathrm{~Hz}, 1 \mathrm{H}), 3.80(\mathrm{~s}, 6 \mathrm{H}), 3.78$ (s, 3H). HRMS (EI) $m / z$ : calcd for $\mathrm{C}_{26} \mathrm{H}_{22} \mathrm{~N}_{4} \mathrm{O}_{3}$ : 438.1692, found: 438.1703 .

4-(furan-2-yl)-2-(methylamino)-6-phenylpyrimidine-5-carbonitrile (19at). Yield: $46 \%$. Mp 193-195 C. ${ }^{1} \mathrm{H}$ NMR (300 MHz, DMSO-d6), $\delta(\mathrm{ppm}):$ 8.42-8.23 (m, 1H), 8.13-8.01 (m, 1H), 7.94- 
$7.74(\mathrm{~m}, 2 \mathrm{H})$, 7.69-7.50 (m, 4H), 6.85-6.76 (m, 1H), 3.39-2.89 (m, 3H). HRMS (EI) m/z: calcd for $\mathrm{C}_{16} \mathrm{H}_{12} \mathrm{~N}_{4} \mathrm{O}: 276.1011$, found: 276.1012.

4-(furan-2-yl)-6-phenyl-2-(phenylamino)pyrimidine-5-carbonitrile (19au). Yield: 48\%. Mp 141-143 ${ }^{\circ} \mathrm{C} .{ }^{1} \mathrm{H}$ NMR (300 MHz, DMSO- $d 6$ ), $\delta(\mathrm{ppm}): 8.14$ (s, 1H), 7.97-7.80 (m, 5H), 7.68-7.55 (m, 4H), $7.35(\mathrm{dd}, J=7.3 \mathrm{~Hz}, 2 \mathrm{H}), 7.06(\mathrm{dd}, J=7.1 \mathrm{~Hz}, 1 \mathrm{H}), 6.90-6.80(\mathrm{~m}, 1 \mathrm{H})$. HRMS (EI) $m / z$ : calcd for $\mathrm{C}_{21} \mathrm{H}_{14} \mathrm{~N}_{4} \mathrm{O}$ : 338.1168 , found: 338.1169 .

2-(methylamino)-4-phenyl-6-(thiophen-2-yl)pyrimidine-5-carbonitrile (19av). Yield: 75\%. Mp 198-199 ${ }^{\circ} \mathrm{C} .{ }^{1} \mathrm{H}$ NMR (300 MHz, $\left.\mathrm{CDCl}_{3}\right), \delta(\mathrm{ppm}): 8.31(\mathrm{~d}, J=3.8 \mathrm{~Hz}, 2 \mathrm{H}), 8.00-7.75(\mathrm{~m}$, $3 \mathrm{H})$, 7.71-7.51 (m, 3H), 7.38-7.26 (m, 1H), 3.08-2.82 (m, 3H). HRMS (EI) $m / z$ : calcd for $\mathrm{C}_{16} \mathrm{H}_{12} \mathrm{~N}_{4} \mathrm{~S}$ : 292.0783, found: 292.0779 .

4-phenyl-2-(phenylamino)-6-(thiophen-2-yl)pyrimidine-5-carbonitrile (19aw). Yield: 46\%. Mp 178-179 ${ }^{\circ} \mathrm{C} .{ }^{1} \mathrm{H}$ NMR (300 MHz, DMSO-d6), $\delta(\mathrm{ppm}): 10.55$ (s, 1H), 8.42-8.31 (m, 1H), 8.08-7.96 (m, 1H), 7.95-7.77 (m, 4H), 7.64-7.53 (m, 3H), 7.44-7.29 (m, 3H), 7.13-7.02 (m, 1H). HRMS (EI) $\mathrm{m} / z$ : calcd for $\mathrm{C}_{21} \mathrm{H}_{14} \mathrm{~N}_{4} \mathrm{~S}: 354.0939$, found: 354.0944 .

4-(furan-3-yl)-2-(methylamino)-6-phenylpyrimidine-5-carbonitrile (19ax). Yield: 65\%. Mp 152-154º C. ${ }^{1} \mathrm{H}$ NMR (300 MHz, DMSO- $\left.d_{6}\right), \delta(\mathrm{ppm}): 8.72-8.42$ (m, $\left.1 \mathrm{H}\right), 8.02-7.75$ (m, 3H), 7.63$7.48(\mathrm{~m}, 3 \mathrm{H}), 7.46-7.41(\mathrm{~m}, 1 \mathrm{H}), 5.70(\mathrm{brs}, 1 \mathrm{H}), 3.16(\mathrm{~d}, J=5.2 \mathrm{~Hz}, 3 \mathrm{H})$. HRMS (EI) $\mathrm{m} / z$ : calcd for $\mathrm{C}_{16} \mathrm{H}_{12} \mathrm{~N}_{4} \mathrm{O}: 276.101$, found: 276.1003 .

4-(furan-3-yl)-6-phenyl-2-(phenylamino)pyrimidine-5-carbonitrile (19ay). Yield: 52\%. Mp 140-142 ${ }^{\circ} \mathrm{C} .{ }^{1} \mathrm{H}$ NMR (300 MHz, DMSO-d6), $\delta$ (ppm): 10.52 (s, 1H), 8.63 (s, 1H), 8.00-7.86 (m, $3 \mathrm{H}), 7.81(\mathrm{~d}, J=8.0 \mathrm{~Hz}, 2 \mathrm{H}), 7.70-7.55(\mathrm{~m}, 3 \mathrm{H}), 7.37(\mathrm{dd}, J=7.5 \mathrm{~Hz}, 2 \mathrm{H}), 7.20(\mathrm{~s}, 1 \mathrm{H}), 7.07(\mathrm{dd}, J$ $=7.0 \mathrm{~Hz}, 1 \mathrm{H})$. HRMS (EI) $\mathrm{m} / z$ : calcd for $\mathrm{C}_{21} \mathrm{H}_{14} \mathrm{~N}_{4} \mathrm{O}: 338.1168$, found: 338.1173 .

2-(methylamino)-4-phenyl-6-(thiophen-3-yl)pyrimidine-5-carbonitrile (19az). Yield: 58\%. Mp 160-162 ${ }^{\circ} \mathrm{C} .{ }^{1} \mathrm{H}$ NMR (300 MHz, $\left.\mathrm{CDCl}_{3}\right), \delta(\mathrm{ppm}): 8.62-8.34$ (m, 1H), 8.06-7.77 (m, 3H), 7.61-7.45 (m, 3H), 7.42 (dd, $J=4.8,2.9 \mathrm{~Hz}, 1 \mathrm{H}), 5.70$ (brs, 1H), 3.14 (d, $J=5.1 \mathrm{~Hz}, 3 \mathrm{H})$. HRMS (EI) $m / z$ : calcd for $\mathrm{C}_{16} \mathrm{H}_{12} \mathrm{~N}_{4} \mathrm{~S}: 292.0783$, found: 292.0787 .

4-phenyl-2-(phenylamino)-6-(thiophen-3-yl)pyrimidine-5-carbonitrile (19ba). Yield: 72\%. Mp 160-162 ${ }^{\circ} \mathrm{C} .{ }^{1} \mathrm{H}$ NMR (300 MHz, $\left.\mathrm{CDCl}_{3}\right), \delta(\mathrm{ppm}): 8.56$ (s, 1H), 8.00-7.94 (m, 2H), 7.74$7.67(\mathrm{~m}, 3 \mathrm{H}), 7.59-7.51(\mathrm{~m}, 4 \mathrm{H}), 7.47-7.36(\mathrm{~m}, 3 \mathrm{H}), 7.19-7.11(\mathrm{~m}, 1 \mathrm{H})$. HRMS (EI) $\mathrm{m} / z$ : calcd for $\mathrm{C}_{21} \mathrm{H}_{14} \mathrm{~N}_{4} \mathrm{~S}$ : 354.0939 , found: 354.0941 .

2-(methylamino)-4-phenyl-6-(pyridin-4-yl)pyrimidine-5-carbonitrile (19bb). Yield: 74\%. Mp 256-258 ${ }^{\circ} \mathrm{C} .{ }^{1} \mathrm{H}$ NMR (300 MHz, DMSO- $\left.d 6\right), \delta(\mathrm{ppm}): 8.80$ (t, $\left.J=4.3 \mathrm{~Hz}, 2 \mathrm{H}\right), 8.47$ (s, 1H), 8.05$7.72(\mathrm{~m}, 4 \mathrm{H}), 7.68-7.49(\mathrm{~m}, 3 \mathrm{H}), 2.96$ (brs, 3H). HRMS (EI) $\mathrm{m} / z$ : calcd for $\mathrm{C}_{17} \mathrm{H}_{13} \mathrm{~N}_{5}: 287.1171$, found: 287.1175 . 
4-phenyl-2-(phenylamino)-6-(pyridin-4-yl)pyrimidine-5-carbonitrile (19bc). Yield: 66\%. Mp 307-308 ${ }^{\circ} \mathrm{C} .{ }^{1} \mathrm{H}$ NMR (300 MHz, DMSO- $\left.d 6\right), \delta(\mathrm{ppm}): 10.71$ (s, 1H), 8.88-8.79 (m, 2H), 8.02-7.93 $(\mathrm{m}, 1 \mathrm{H}), 7.88(\mathrm{~d}, J=5.9 \mathrm{~Hz}, 2 \mathrm{H}), 7.79(\mathrm{~d}, J=7.7 \mathrm{~Hz}, 2 \mathrm{H}), 7.67-7.53(\mathrm{~m}, 4 \mathrm{H}), 7.34(\mathrm{dd}, J=7.7 \mathrm{~Hz}$, 2H), 7.07 (dd, $J=7.4 \mathrm{~Hz}, 1 \mathrm{H}$ ). HRMS (EI) $m / z$ : calcd for $\mathrm{C}_{22} \mathrm{H}_{15} \mathrm{~N}_{5}: 349.1327$, found: 349.1312 .

2-(methylamino)-4-phenyl-6-(pyridin-3-yl)pyrimidine-5-carbonitrile (19bd). Yield: 43\%. Mp 248-249 ${ }^{\circ} \mathrm{C} .{ }^{1} \mathrm{H}$ NMR (300 MHz, DMSO-d6), $\delta$ (ppm): 9.05 (brs, 1H), 8.78-8.74 (m, 1H), 8.44 (m, $1 \mathrm{H}), 8.34-8.23(\mathrm{~m}, 1 \mathrm{H}), 7.97-7.85(\mathrm{~m}, 2 \mathrm{H}), 7.62-7.54(\mathrm{~m}, 4 \mathrm{H}), 2.96(\mathrm{~d}, J=4.7 \mathrm{~Hz}, 3 \mathrm{H}) .{ }^{13} \mathrm{C}$ NMR $(75$ MHz, DMSO-d6) $\delta(\mathrm{ppm}): 187.9,170.3,168.9,161.6,151.7,149.4,136.4,132.7,131.2,128.9,123.5$, 118.6, 112.3, 91.3, 28.0. HRMS (ESI) $m / z$ : calcd for: $\mathrm{C}_{17} \mathrm{H}_{13} \mathrm{~N}_{5}[\mathrm{M}+\mathrm{H}]^{+} 288.1249$, found: 288.1244.

2-(ethylamino)-4-phenyl-6-(pyridin-3-yl)pyrimidine-5-carbonitrile (19be). Yield: 48\%. Mp 152-153 ${ }^{\circ} \mathrm{C} .{ }^{1} \mathrm{H}$ NMR (300 MHz, $\left.\mathrm{CDCl}_{3}\right), \delta(\mathrm{ppm}):$ 8.58-8.49 (m, 1H), 7.98-7.80 (m, 4H), 7.70$7.52(\mathrm{~m}, 5 \mathrm{H}), 3.50-3.38(\mathrm{~m}, 2 \mathrm{H}), 1.17(\mathrm{t}, J=7.1 \mathrm{~Hz}, 3 \mathrm{H}) .{ }^{13} \mathrm{C}$ NMR $(75 \mathrm{MHz}, \mathrm{DMSO}-d 6) \delta(\mathrm{ppm})$ : 169.8, 136.8, 131.1, 129.0, 128.5, 123.5, 107.0, 93.1, 36.9. MS (EI) m/z: $301.0\left(\mathrm{M}^{+}, 91\right), 300.0$ (100), 286.0 (48), 273.0 (19), 272.0 (78), 258.0 (21), 129.0 (21), 77.0 (16).

4-phenyl-2-(phenylamino)-6-(pyridin-3-yl)pyrimidine-5-carbonitrile (19bf). Yield: 42\%. Mp 245-246 ${ }^{\circ} \mathrm{C} .{ }^{1} \mathrm{H}$ NMR (300 MHz, DMSO-d6), $\delta$ (ppm): $10.68(\mathrm{~s}, 1 \mathrm{H}), 9.14(\mathrm{~d}, J=2.0 \mathrm{~Hz}, 1 \mathrm{H})$, 8.85-8.76 (m, 1H), 8.37 (dt, $J=8.1,1.9 \mathrm{~Hz}, 1 \mathrm{H}), 8.07-7.94(\mathrm{~m}, 2 \mathrm{H}), 7.81$ (d, $J=8.6 \mathrm{~Hz}, 2 \mathrm{H}), 7.68$ $7.58(\mathrm{~m}, 4 \mathrm{H}), 7.36(\mathrm{dd}, J=8.0 \mathrm{~Hz}, 2 \mathrm{H}), 7.08(\mathrm{dd}, J=7.4 \mathrm{~Hz}, 1 \mathrm{H})$. HRMS (EI) $m / z$ : calcd for $\mathrm{C}_{22} \mathrm{H}_{15} \mathrm{~N}_{5}$ 349.1327, found: 349.1328 .

4-cyclohexyl-2-(methylamino)-6-phenylpyrimidine-5-carbonitrile (19bg). Yield: 51\%. Mp 204-205 ${ }^{\circ} \mathrm{C} .{ }^{1} \mathrm{H}$ NMR $\left(300 \mathrm{MHz}, \mathrm{CDCl}_{3}\right), \delta$ (ppm): 7.99-7.92 (m, 1H), 7.85-7.78 (m, 1H), 7.49-7.24 $(\mathrm{m}, 3 \mathrm{H})$, 5.67-5.53 (m, 1H), 3.09-3.04 (m, 4H), 1.82-1.23 (m, 10H). HRMS (EI) m/z: calcd for $\mathrm{C}_{18} \mathrm{H}_{20} \mathrm{~N}_{4}: 292.1610$, found: 292.1688 .

4-cyclohexyl-6-phenyl-2-(phenylamino)pyrimidine-5-carbonitrile (19bh). Yield: 67\%. Mp 118-120 ${ }^{\circ} \mathrm{C} .{ }^{1} \mathrm{H}$ NMR (300 MHz, $\left.\mathrm{CDCl}_{3}\right), \delta(\mathrm{ppm}): 7.59$ (d, $\left.J=6.70 \mathrm{~Hz}, 2 \mathrm{H}\right), 7.39-7.32(\mathrm{~m}, 6 \mathrm{H}), 7.18$ (t, $J=7.44 \mathrm{~Hz}, 1 \mathrm{H}), 6.99$ (d, $J=7.55 \mathrm{~Hz}, 2 \mathrm{H}), 3.92(\mathrm{~s}, 1 \mathrm{H}), 1.86-0.85$ (m, 10H). MS (EI) $m / z: 354.17$ $\left(\mathrm{M}^{+}, 22\right), 353.15$ (17), $274.1(50), 273.1$ (100).

4,6-bis(3-chlorophenyl)-2-(methylamino)pyrimidine-5-carbonitrile (19bi). Yield: 42\%. Mp 255-257º ${ }^{1}{ }^{1} \mathrm{H}$ NMR (300 MHz, DMSO-d6), $\delta(\mathrm{ppm}): 8.50$ (q, $\left.J=4.2 \mathrm{~Hz}, 1 \mathrm{H}\right), 7.99$ (t, $J=1.9 \mathrm{~Hz}$, $1 \mathrm{H}), 7.94-7.88(\mathrm{~m}, 2 \mathrm{H}), 7.84(\mathrm{dt}, J=7.3,1.5 \mathrm{~Hz}, 1 \mathrm{H}), 7.72-7.54(\mathrm{~m}, 4 \mathrm{H}), 2.95(\mathrm{~d}, J=4.8 \mathrm{~Hz}, 3 \mathrm{H})$. HRMS (EI) $m / z$ : calcd for $\mathrm{C}_{18} \mathrm{H}_{12} \mathrm{Cl}_{2} \mathrm{~N}_{4}: 354.0439$, found: 354.0434 .

4,6-bis(3-chlorophenyl)-2-(phenylamino)pyrimidine-5-carbonitrile (19bj). Yield: 52\%. Mp 211-213으. ${ }^{1} \mathrm{H}$ NMR (300 MHz, DMSO-d6), $\delta(\mathrm{ppm}): 10.71(\mathrm{~s}, 1 \mathrm{H}), 8.03(\mathrm{~s}, 1 \mathrm{H}), 7.94(\mathrm{~d}, J=7.2$ 
$\mathrm{Hz}, 2 \mathrm{H}), 7.83-7.60(\mathrm{~m}, 7 \mathrm{H}), 7.35(\mathrm{dd}, J=7.9 \mathrm{~Hz}, 2 \mathrm{H}), 7.08$ (dd, $J=7.9 \mathrm{~Hz}, 1 \mathrm{H}) . \mathrm{MS}(\mathrm{EI}) \mathrm{m} / z: 420.1$ (36), 418.1 (72), $417.1(83), 416.1\left(\mathrm{M}^{+}, 100\right), 415.1(88), 381.0$ (13).

\section{4-(3-chlorophenyl)-6-(3,5-dichlorophenyl)-2-(methylamino)pyrimidine-5-carbonitrile}

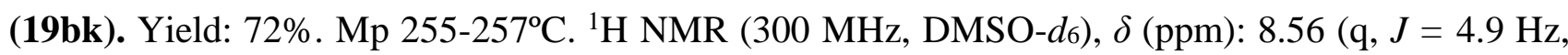
1H), 8.04-7.79 (m, 5H), 7.74-7.56 (m, 2H), $2.95(\mathrm{~d}, J=4.5 \mathrm{~Hz}, 3 \mathrm{H})$. HRMS (EI) $m / z$ : calcd for $\mathrm{C}_{18} \mathrm{H}_{11} \mathrm{Cl}_{3} \mathrm{~N}_{4}: 388.0049$, found: 388.0048 .

4-(3-chlorophenyl)-6-(3,5-dichlorophenyl)-2-(phenylamino)pyrimidine-5-carbonitrile (19bl). Yield: 56\%. Mp 199-201 ${ }^{\circ} \mathrm{C} .{ }^{1} \mathrm{H}$ NMR (300 MHz, DMSO- $\left.d 6\right), \delta(\mathrm{ppm}): 8.13-8.05$ (m, 2H), 7.88$7.82(\mathrm{~m}, 2 \mathrm{H}), 7.68(\mathrm{~d}, J=8.7 \mathrm{~Hz}, 2 \mathrm{H}), 7.59-7.54(\mathrm{~m}, 3 \mathrm{H}), 7.42-7.37(\mathrm{~m}, 2 \mathrm{H}), 7,16(\mathrm{t}, J=8.4 \mathrm{~Hz}, 1 \mathrm{H})$. MS (EI) m/z: 456.2 (10), 454.2 (40) 452.2 (96), $450.2\left(\mathrm{M}^{+}, 100\right), 415.2$ (44), 386.2 (28).

4,6-bis(4-methoxyphenyl)-2-(methylamino)pyrimidine-5-carbonitrile (19bm). Yield: 70\%. Mp 249-250 ${ }^{\circ} \mathrm{C} .{ }^{1} \mathrm{H}$ NMR (300 MHz, $\left.\mathrm{CDCl}_{3}\right), \delta(\mathrm{ppm}): 8.08(\mathrm{~d}, J=7.2 \mathrm{~Hz}, 2 \mathrm{H}), 7.93$ (d, $J=7.2$ Hz, 2H), 7.03 (d, $J=7.2 \mathrm{~Hz}, 4 \mathrm{H}), 5.64(\mathrm{~s}, 1 \mathrm{H}), 3.88(\mathrm{~s}, 6 \mathrm{H}), 3.15$ (d, $J=5.0 \mathrm{~Hz}, 3 \mathrm{H}) . \mathrm{HRMS}(\mathrm{EI}) \mathrm{m} / z$ : calcd for $\mathrm{C}_{20} \mathrm{H}_{18} \mathrm{~N}_{4} \mathrm{O}_{2}: 346.1430$, found: 346.1435 .

4,6-bis(4-methoxyphenyl)-2-(phenylamino)pyrimidine-5-carbonitrile (19bn). Yield: 48\%. Mp 210-211 ${ }^{\circ} \mathrm{C} .{ }^{1} \mathrm{H}$ NMR (300 MHz, $\left.\mathrm{CDCl}_{3}\right), \delta$ (ppm): 10.50 (bs, $\left.1 \mathrm{H}\right), 7.97$ (d, $\left.J=8.7 \mathrm{~Hz}, 4 \mathrm{H}\right), 7.82$ $(\mathrm{d}, J=7.6 \mathrm{~Hz}, 2 \mathrm{H}), 7.33(\mathrm{~m}, 2 \mathrm{H}), 7.13(\mathrm{~d}, J=8.7 \mathrm{~Hz}, 4 \mathrm{H}), 7.05(\mathrm{t}, J=7.6 \mathrm{~Hz}, 1 \mathrm{H}), 3.85(\mathrm{~s}, 6 \mathrm{H}) .{ }^{13} \mathrm{C}$ NMR (75 MHz, $\left.\mathrm{CDCl}_{3}\right) \delta$ (ppm): 169.7, 161.8, 159.0, 139.3, 131.0, 128.8, 123.1, 120.3, 119.0, 114.0, 91.8, 55.6. HRMS (ESI) $\mathrm{m} / z$ : calcd for $\mathrm{C}_{25} \mathrm{H}_{20} \mathrm{~N}_{4} \mathrm{O}_{2}[\mathrm{M}+\mathrm{H}]^{+}$: 409.1665, found: 409.1659.

2-(dimethylamino)-4,6-diphenylpyrimidine-5-carbonitrile (20a). Yield: 46\%. Mp 233$234^{\circ} \mathrm{C} .{ }^{1} \mathrm{H}$ NMR (300 MHz, DMSO- $\left.d 6\right), \delta(\mathrm{ppm}):$ 7.99-7.86 (m, 4H), 7.60-7.55 (m, 6H), 3.29 (s, 6H). ${ }^{13} \mathrm{C}$ NMR (75 MHz, DMSO- $\left.d 6\right) \delta$ (ppm): 169.8, 136.8, 131.1, 129.0, 128.5, 123.5, 107.0, 93.1, 36.9. HRMS (ESI) $m / z$ : calcd for $\mathrm{C}_{19} \mathrm{H}_{16} \mathrm{~N}_{4}[\mathrm{M}+\mathrm{H}]^{+}:$301.1453, found: 301.1448 .

4-(3-chlorophenyl)-2-(dimethylamino)-6-phenylpyrimidine-5-carbonitrile (20b). Yield: 42\%. Mp 178-179 ${ }^{\circ} \mathrm{C} .{ }^{1} \mathrm{H}$ NMR (300 MHz, DMSO- $\left.d 6\right), \delta(\mathrm{ppm}): 7.94-7.86$ (m, 4H), 7.66-7.52 (m, 5H), 3.27 (s, 6H). ${ }^{13} \mathrm{C}$ NMR (75 MHz, DMSO-d6) $\delta$ (ppm): 170.1, 168.7, 160.5, 139.1, 137.0, 133.6, 131.5, 131.2, 130.8, 129.3, 129.0, 128.9, 128.0, 119.0, 90.3, 37.3. HRMS (ESI) $\mathrm{m} / \mathrm{z}$ : calcd for $\mathrm{C}_{19} \mathrm{H}_{15} \mathrm{ClN}_{4}$ $[\mathrm{M}+\mathrm{H}]^{+}:$335.0985, found: 335.0991 .

2-(dimethylamino)-4-(4-fluorophenyl)-6-phenylpyrimidine-5-carbonitrile (20c). Yield: 73\%. Mp 237-238 ${ }^{\circ} \mathrm{C} .{ }^{1} \mathrm{H}$ NMR (300 MHz, DMSO- $d 6$ ), $\delta$ (ppm): 8.04-8.01 (m, 2H), 7.99-7.91 (m, 2H), 7.57-7.55 (m, 3H), 7.43-7.37 (m, 2H), $2.48(\mathrm{~s}, 3 \mathrm{H}), 2.47$ (s, 3H). ${ }^{13} \mathrm{C}$ NMR (75 MHz, DMSO-d6) $\delta$ (ppm): 170.2, 169.7, 160.6, 137.1, 133.6, 132.0, 131.5, 129.3, 128.9, 119.2, 116.1, 115.8, 90.3, 37.3. HRMS (ESI) $m / z$ : calcd for $\mathrm{C}_{19} \mathrm{H}_{15} \mathrm{~N}_{4} \mathrm{~F}[\mathrm{M}+\mathrm{H}]^{+}: 319.1359$, found: 319.1354 . 


\section{Supplementary Figures}

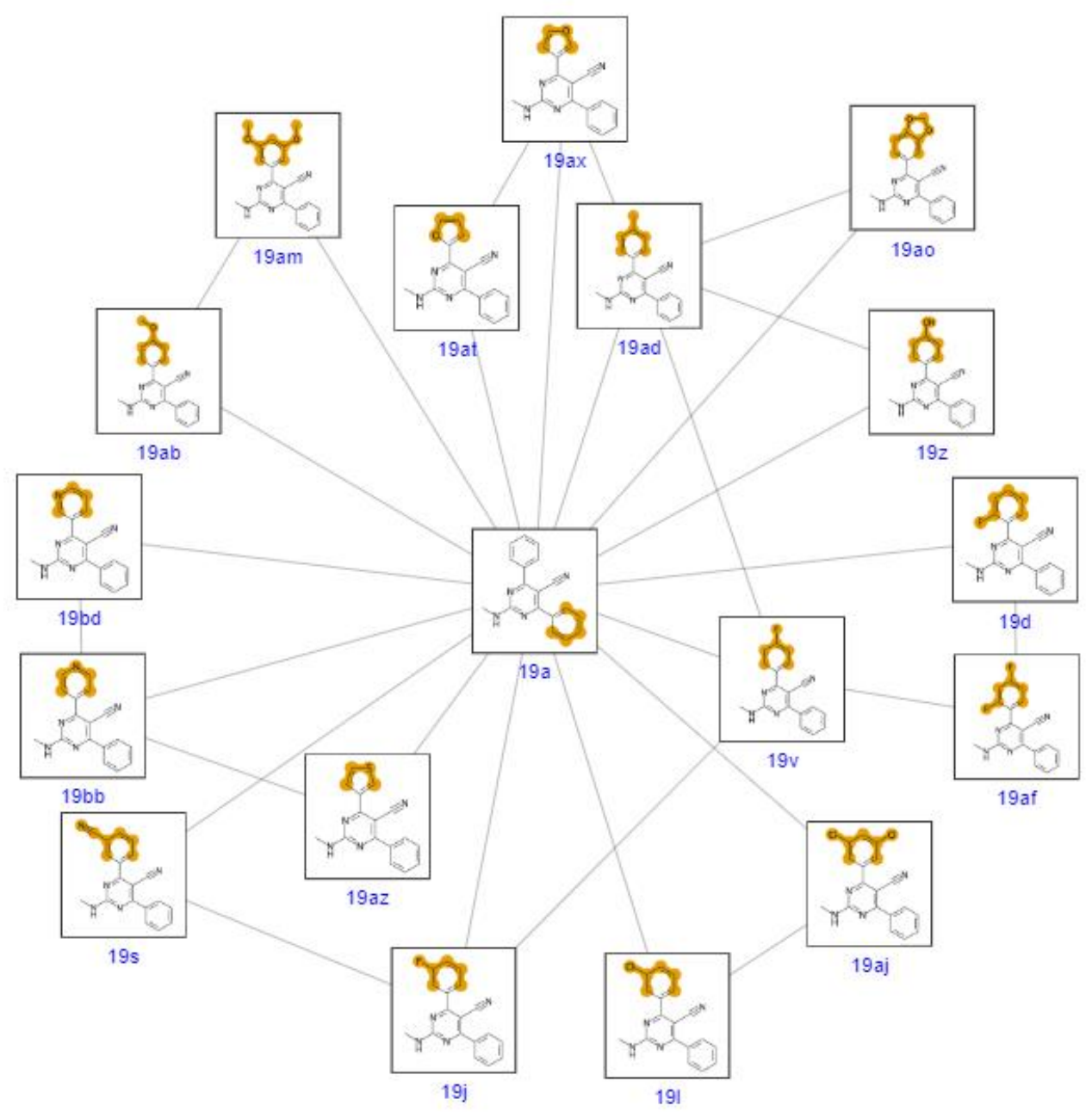

Supplementary Figure 1. FEP pathway used along this study: The 18 compounds (nodes) were characterized with a total of and 29 alchemical transformations (edges) between selected compound pairs. An ulterior cycle closure correction allows the conversion of the 29 calculated $\Delta \Delta G_{\text {binding }}$ between compound pairs, into estimates of the absolute binding affinity ( $\Delta G_{\text {bind }}$ ) for each compound. 


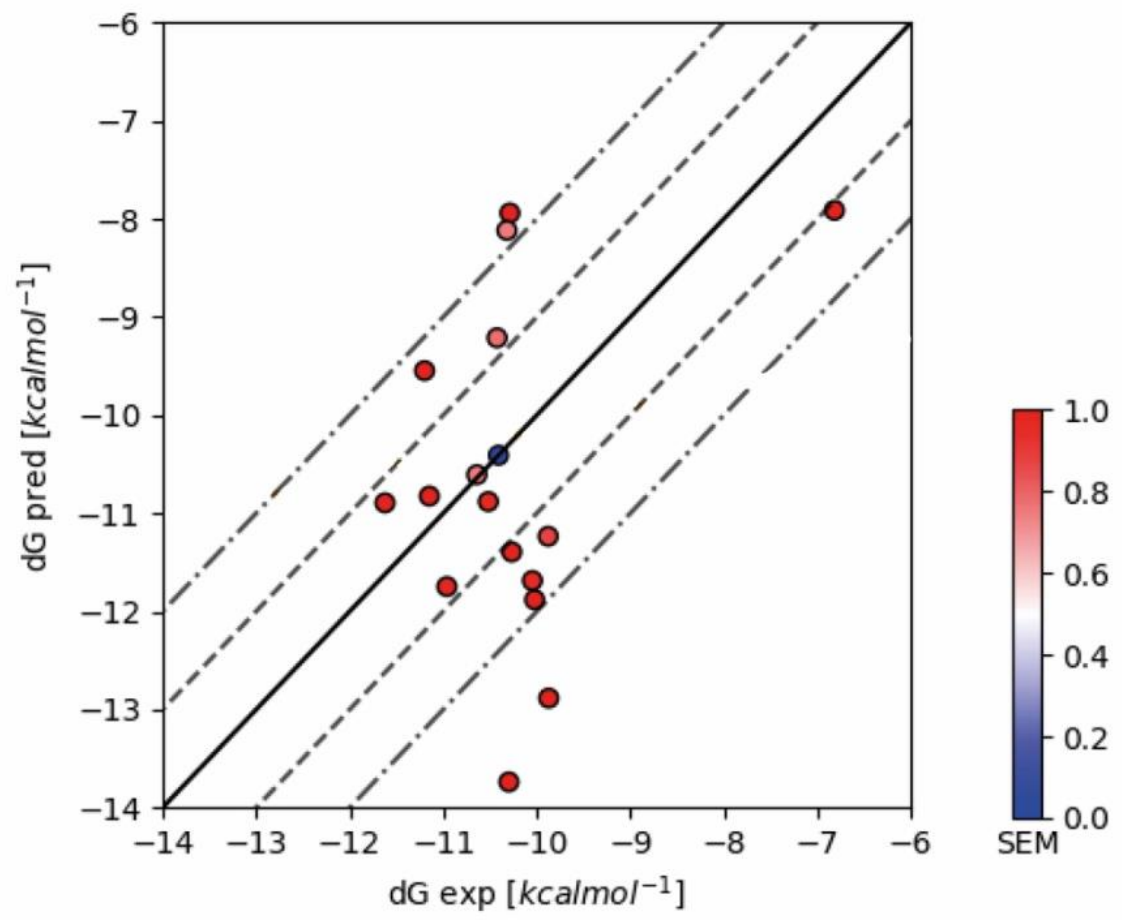

Supplementary Figure 2. Scatter plot of the predicted vs experimental binding affinities for the $\mathrm{A}_{1} \mathrm{AR}$, as determined by FEP calculations using conformation B. Statistical data: MAE $=1.68 \pm$ $0.39, \operatorname{RMSE}=2.26 \pm 0.59, \mathrm{SEM} 1.12 \pm 0.1$. Confidence intervals for the regression metrics were estimated using bootstrap sampling. 


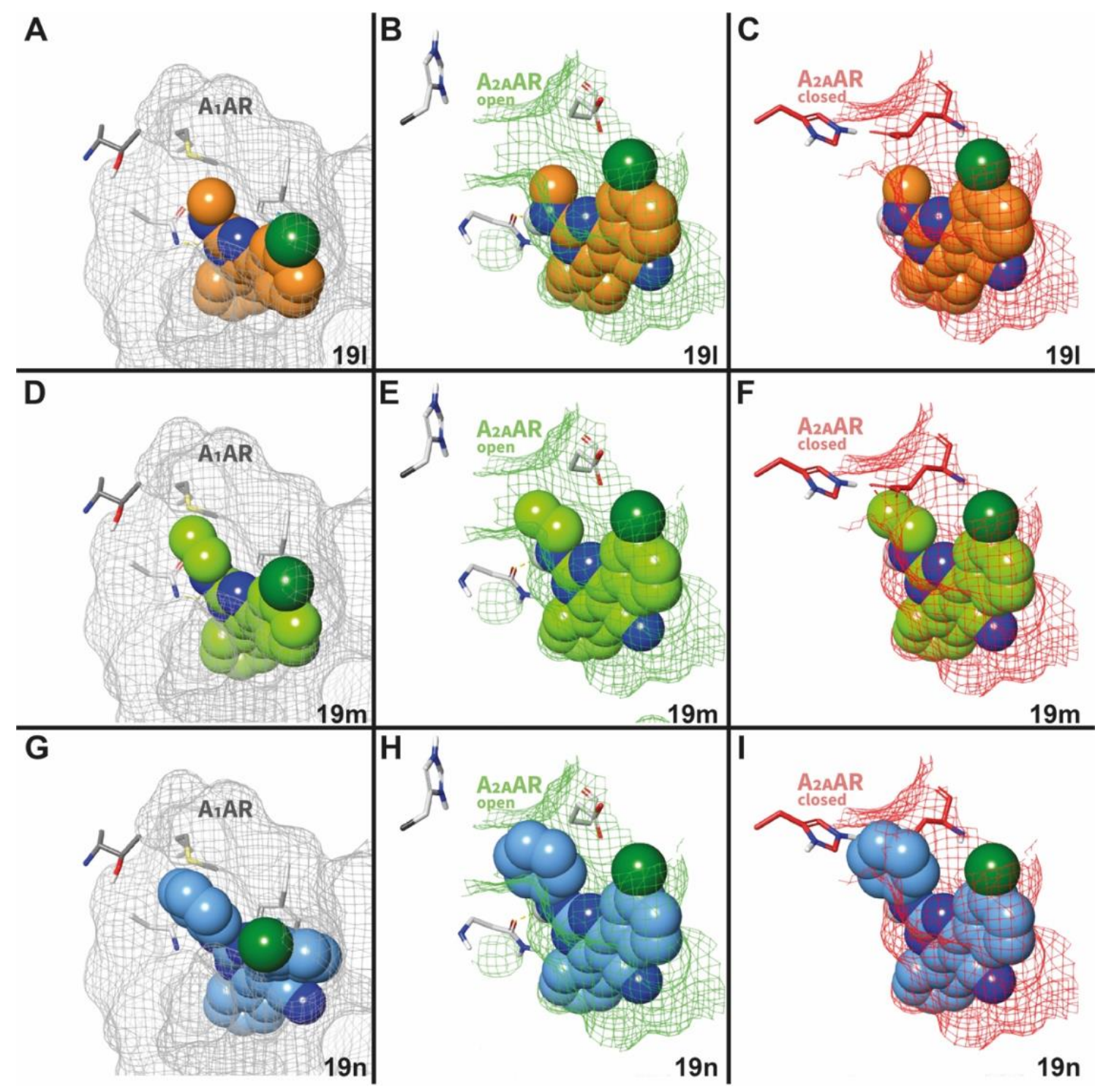

Supplementary Figure 3. Surface and balls representation for ligands N-substituted. A, B and C) 191 binding $\mathrm{A}_{1} \mathrm{AR}, \mathrm{A}_{2 \mathrm{~A}} \mathrm{AR}$ (open, rotamers from PDB: $3 \mathrm{uzc}$ ) and $\mathrm{A}_{2 \mathrm{~A}} \mathrm{AR}$ (closed, PDB: 4eiy) respectively. $\mathrm{N}$-methylation allows efficient binding in $\mathrm{A}_{1} \mathrm{AR}$ but difficult binding in $\mathrm{A}_{2 \mathrm{~A}} \mathrm{AR}$ closed, not stabilizing $\mathrm{A}_{2 \mathrm{~A} A R}$ open. D, E and F) $19 \mathrm{~m}$ binding $\mathrm{A}_{1} \mathrm{AR}, \mathrm{A}_{2 \mathrm{~A}} \mathrm{AR}$ (open, rotamers from PDB: 3uzc) and $\mathrm{A}_{2 \mathrm{AAR}}$ (closed, PDB: 4eiy) respectively. N-ethylation allows binding in A1 AR but difficult binding in A2AAR closed, slightly stabilizing A2AAR open. G, H and I) 19n binding A 1 AR, A2AAR (open, rotamers from PDB: 3uzc) and A2AAR (closed, PDB: 4eiy) respectively. N-phenylation causes a loss of a hydrogen bond by rearrangement of the molecule in $\mathrm{A}_{1} \mathrm{AR}$ but strongly stabilizes $\mathrm{A}_{2 \mathrm{~A}} \mathrm{AR}$ open. 

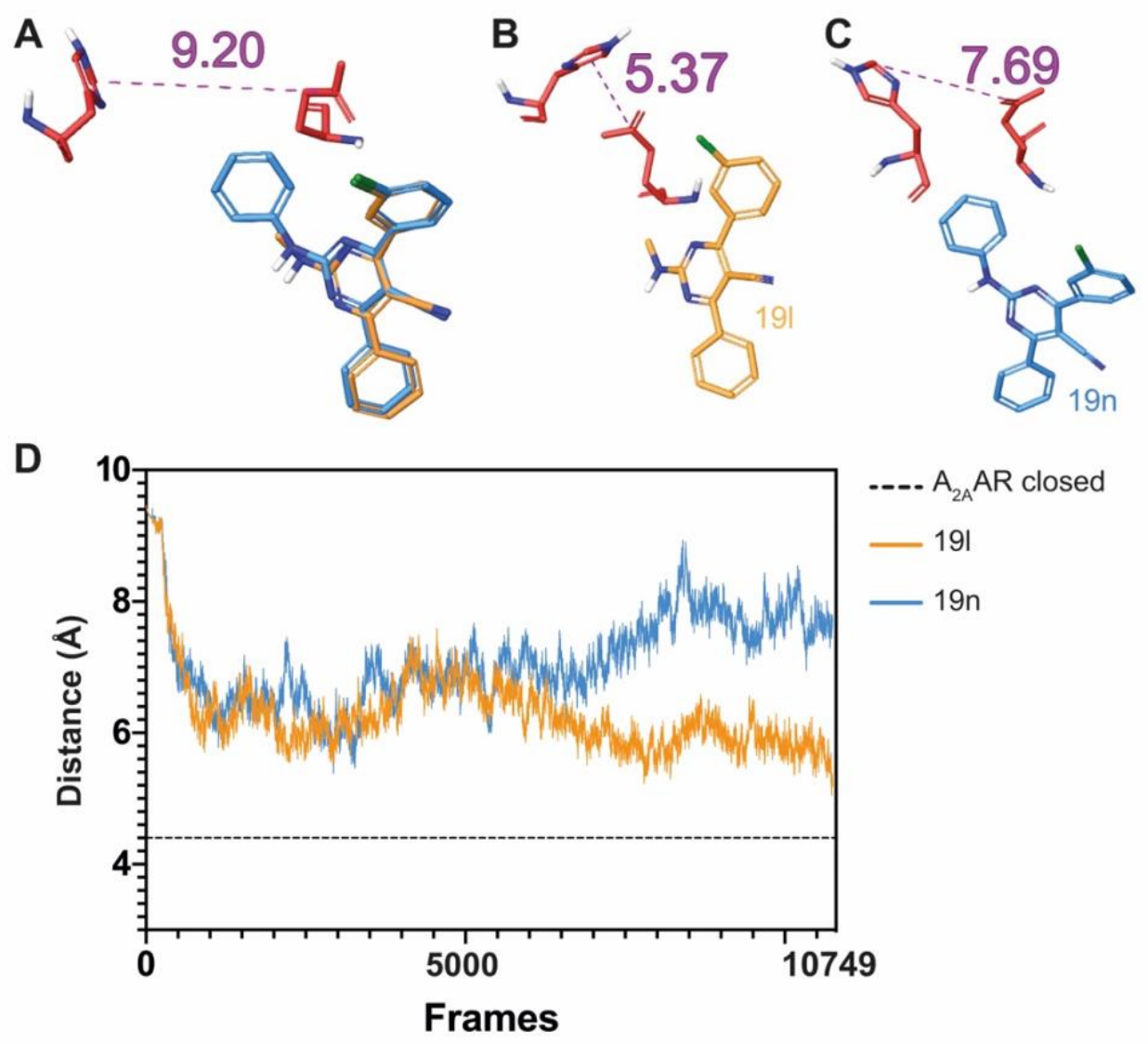

Supplementary Figure 4. A. Initial state at $\mathrm{A}_{2 \mathrm{~A}} \mathrm{AR}$ conformation in $\mathrm{MD}$ simulations. Distance between C-His $264^{\mathrm{EL} 3}$ and CO-Glu169 ${ }^{\mathrm{EL} 2}$ in $\AA$. B. Final state conformation of 191 ( $N$-methyl compound) at $\mathrm{A}_{2 \mathrm{~A}} \mathrm{AR}$. C. Final state conformation of $19 \mathrm{n}$ ( $N$-phenyl compound) at $\mathrm{A}_{2 \mathrm{~A}} \mathrm{AR}$. D. Distance between C-His $264^{\mathrm{EL} 3}$ and COGlu $169^{\mathrm{EL} 2}$ in $\AA$ in MD simulations. 191 (orange) does not able to keep the $\mathrm{A}_{2 \mathrm{~A}} \mathrm{AR}$ open, but 19n (blue) stabilized the open $\mathrm{A}_{2 \mathrm{~A}} \mathrm{AR}$ open conformation. 


\section{Supplementary Tables}

The functional profile of selected ligands $(19 \mathrm{ao}, 19 \mathrm{l}$ and $19 \mathrm{v})$ was evaluated in cAMP assays following experimental procedures previously reported by us. ${ }^{2,3,4}$

Supplementary Table 1. Functional studies of 19ao, 19l, 19v (at the four adenosine receptors).

\begin{tabular}{|c|c|c|c|c|}
\hline & $h \mathrm{~A}_{1}$ & $h \mathrm{~A}_{2 \mathrm{~A}^{2}}$ & $h \mathrm{~A}_{2 \mathrm{~B}^{3}}$ & $h \mathbf{A}_{3}{ }^{4}$ \\
\hline Compound & $\mathbf{K b}(\mathbf{n M})$ & $\begin{array}{c}\text { \% Inhib. NECA } \\
\qquad(1 \mu \mathrm{M})\end{array}$ & $\begin{array}{c}\text { \% Inhib. NECA } \\
\qquad(1 \mu \mathrm{M})\end{array}$ & $\begin{array}{c}\text { \% Inhib. NECA } \\
(1 \mu \mathrm{M})\end{array}$ \\
\hline 19l & 6.21 & $16 \%$ & $11 \%$ & $9 \%$ \\
\hline $19 v$ & 9.72 & $25 \%$ & $1 \%$ & $5 \%$ \\
\hline 19ao & 3.90 & $18 \%$ & $1 \%$ & $5 \%$ \\
\hline
\end{tabular}

Human Microsomal Stability. The human microsomes employed were purchased from TebuXenotech. The compound was incubated with microsomes at $37{ }^{\circ} \mathrm{C}$ in a $50 \mathrm{mM}$ phosphate buffer $(\mathrm{pH}$ =7.4) containing $30 \mathrm{mM} \mathrm{MgCl}_{2}, 10 \mathrm{mM}$ NADP, $100 \mathrm{mM}$ glucose-6-phosphate, and $40 \mathrm{U} / \mathrm{mL}$ glucose6-phosphate dehydrogenase. Samples $(75 \mu \mathrm{L})$ were taken from each well at 0, 10, 20, 40, and $60 \mathrm{~min}$ and transferred to a plate containing $75 \mu \mathrm{L}$ of acetonitrile $\left(4^{\circ} \mathrm{C}\right)$, and $30 \mu \mathrm{L}$ of $0.5 \%$ formic acid in water was added for improving the chromatographic conditions. The plate was centrifuged (4000g, 60 min) and supernatants were taken and analyzed in a UPLC-MS/MS (Xevo-TQD, Waters) by employing a BEH C18 column and an isocratic gradient of $0.1 \%$ formic acid in water: $0.1 \%$ formic acid acetonitrile (60:40). The metabolic stability of the compounds was calculated from the logarithm of the remaining compounds at each of the time points studied.

Supplementary Table 2. Stability parameters obtained for each of the studied compounds.

\begin{tabular}{cccc}
\hline Compound & $\begin{array}{c}\text { \% Remanent } \\
(\text { sampling time 60 } \mathbf{~ m i n})\end{array}$ & $\begin{array}{c}\text { tuman } \\
(\mathbf{m i n})\end{array}$ & $\begin{array}{c}\mathbf{C L}_{\text {int }} \\
\left(\boldsymbol{\mu L} \cdot \mathbf{m g}_{\text {protein }}{ }^{-1} \cdot \mathbf{m i n}^{-\mathbf{1}}\right)\end{array}$ \\
\hline $\mathbf{1 9 l}$ & 3.7 & 6.24 & 27.78 \\
19v & 15.1 & 18.65 & 32.41 \\
19ao & 11.4 & 15.24 & 50.28 \\
Testosterone & 8.77 & 17.09 & 27.78
\end{tabular}


Supplementary Table 3. pKi of compounds selected for docking studies. The selection criteria were based on the primary structure of the novel compounds. Taking the compounds that show affinity data (Ki), the pKi $\left[-\log \left(K_{i}\right)\right]$ was calculated for both receptors and with all the $\mathrm{R}^{2}$ substitutions $(\mathrm{H}, \mathrm{Me}$, Et, $\mathrm{Ph})$ analogues. With this, $\Delta \mathrm{pKi}$ was calculated as $\Delta p K i_{\text {receptor }}=p K_{i}\left(R_{2}=H\right)_{\text {receptor }}-$ $p K_{i}\left(R_{2} \neq H\right)_{\text {receptor }}$ for $\mathrm{A}_{1} \mathrm{AR}$ and $\mathrm{A}_{2 \mathrm{AAR}} \mathrm{AR}$. With this data, $\Delta \Delta \mathrm{pKi}$ was calculated as $\Delta \Delta p K i_{R_{2}}=$ $\Delta p K i_{A_{2 A}}-\Delta p K i_{A_{1}}$. Pairs of compounds showing more difference between the $\mathrm{H}$ and the $\mathrm{R}^{2}$ (the largest absolute values of $\Delta \Delta \mathrm{pKi}$ ) was selected with the same scaffold compounds for docking studies (Graphic below). N-methylated compounds with this scaffold was selected for FEP studies.

\begin{tabular}{|c|c|c|c|c|c|c|c|c|c|c|c|c|c|c|c|c|c|c|c|}
\hline \multirow{2}{*}{$\mathbf{H}$} & $\mathbf{A}_{\mathbf{1}}$ & 8.4 & 8.2 & 7.9 & 8.4 & 8.2 & 8.4 & 8.1 & 8.4 & 8.3 & 8.4 & 7.8 & 8.6 & 8.8 & 8.0 & 7.7 & 8.3 & 6.7 & 7.7 \\
\hline & $\mathbf{A}_{2 \mathrm{~A}}$ & 8.1 & 7.8 & 7.7 & 7.8 & 7.1 & 7.8 & 7.3 & 7.6 & 8.0 & 7.8 & 7.0 & 8.8 & 8.0 & 8.0 & 7.3 & 7.7 & 8.2 & 8.1 \\
\hline \multirow{2}{*}{ Me } & $\mathbf{A}_{1}$ & 8.0 & 7.5 & 7.5 & 7.8 & 8.5 & 7.6 & 7.2 & 7.4 & 7.6 & 7.6 & 7.6 & 8.0 & 8.2 & 8.2 & 5.0 & 7.4 & 7.2 & 7.7 \\
\hline & $\mathbf{A}_{2 \mathrm{~A}}$ & 6.1 & 5.0 & 5.0 & 5.0 & 7.1 & 5.0 & 5.0 & 5.0 & 5.0 & 5.0 & 5.0 & 7.9 & 5.0 & 6.4 & 5.0 & 5.0 & 5.0 & 5.0 \\
\hline \multirow{2}{*}{ Et } & $\mathbf{A}_{\mathbf{1}}$ & 8.2 & - & - & 8.3 & 8.6 & - & - & - & - & - & 6.9 & - & 8.2 & - & - & - & - & 7.9 \\
\hline & $\mathbf{A}_{2 \mathrm{~A}}$ & 6.4 & - & - & 6.5 & 6.8 & - & - & - & - & - & 5.0 & - & 6.0 & - & - & - & - & 8.1 \\
\hline \multirow{2}{*}{$\mathbf{P h}$} & $\mathbf{A}_{1}$ & 7.3 & 8.2 & 5.0 & 5.0 & 7.7 & 7.4 & 5.0 & 5.0 & 7.4 & 5.0 & 5.0 & 5.0 & 7.9 & 7.5 & 5.0 & 5.0 & 5.0 & 5.0 \\
\hline & $\mathbf{A}_{2 \mathrm{~A}}$ & 7.3 & 7.3 & 5.0 & 8.3 & 5.0 & 5.0 & 7.3 & 5.0 & 6.8 & 5.0 & 5.0 & 7.8 & 7.6 & 8.7 & 6.4 & 7.0 & 5.0 & 8.3 \\
\hline
\end{tabular}

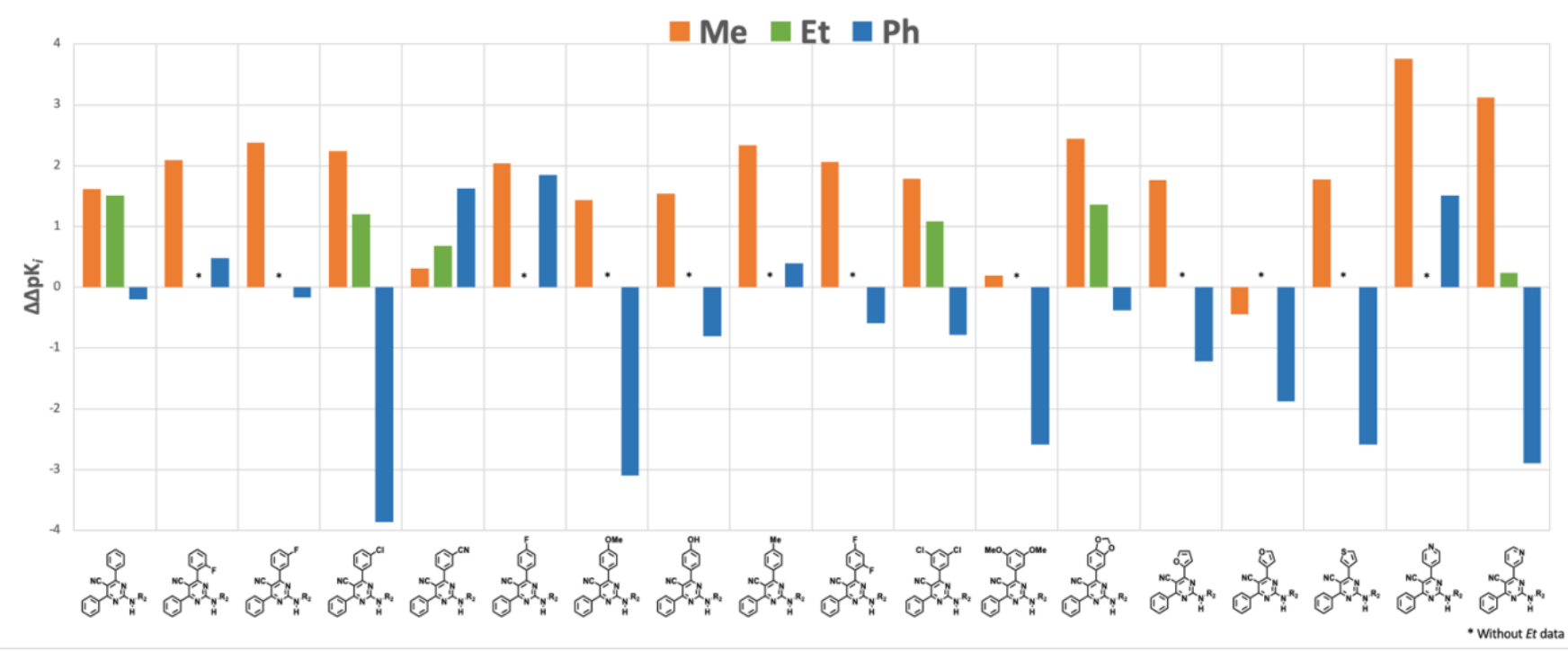


Supplementary Table 4. Calculated and experimental relative binding affinity ( $\Delta \Delta G_{\text {bind) }}$ between the pairs of compounds defined in the FEP pathway defined in Supplementary Figure 2. Errors are defined as standard error of the mean (sem) from 10 independent simulations. UE indicates the unnasigned error as compared to experiment (Exp) on each conformation modelled (A or B)

\begin{tabular}{ccrcccc}
\hline Lig 1 & Lig 2 & Exp & \multicolumn{2}{c}{ Conformation A } & \multicolumn{2}{c}{ Conformation B } \\
& & $\Delta \Delta G$ bind & $\Delta \Delta G$ bind & UE & $\Delta \Delta G_{\text {bind }}$ & UE \\
\hline 19a & 19ab & 1,09 & $0.83 \pm 0.45$ & 0.26 & $-1.14 \pm 1.01$ & 2,23 \\
19a & 19aj & 0,64 & $-2.54 \pm 0.16$ & 3.18 & $3,63 \pm 0,09$ & 2,99 \\
19a & 19am & 0,11 & $-1.98 \pm 0,57$ & 2,09 & $8,09 \pm 1,01$ & 7,98 \\
19a & 19ao & $-0,24$ & $-0.55 \pm 0.36$ & 0.31 & $2.20 \pm 1.25$ & 2.44 \\
19a & 19at & -0.19 & $0.49 \pm 0.25$ & 0.68 & $0.92 \pm 1.25$ & 1.11 \\
19a & 19ax & 4.14 & $0.94 \pm 0.18$ & 3.20 & $3.83 \pm 1.14$ & 0.31 \\
19a & 19az & 0.91 & $-1.28 \pm 0.17$ & 2.19 & $0.06 \pm 0.39$ & 0.85 \\
19a & 19bb & 1.08 & $-0.16 \pm 0.18$ & 1.24 & $0.51 \pm 0.27$ & 0.57 \\
19a & 19bd & 0.44 & $-0.30 \pm 0.13$ & 0.74 & $0.87 \pm 0.39$ & 0.42 \\
19a & 19d & 0.69 & $0.20 \pm 0.15$ & 0.49 & $0.35 \pm 0.78$ & 0.34 \\
19a & 19j & 0.67 & $0.01 \pm 0.21$ & 0.66 & $3.81 \pm 0.87$ & 3.13 \\
19a & 19l & 0.32 & $-0.57 \pm 0.16$ & 0.89 & $1.14 \pm 0.09$ & 0.82 \\
19a & 19s & -0.66 & $-1.39 \pm 0.43$ & 0.73 & $0.85 \pm 1.17$ & 1.52 \\
19a & 19v & 0.55 & $0.95 \pm 0.13$ & 0.40 & $1.34 \pm 0.98$ & 0.79 \\
19a & 19z & 0.94 & $0.93 \pm 0.21$ & 0.01 & $-0.14 \pm 0.87$ & 1.07 \\
19ab & 19am & -0.98 & $-3.20 \pm 0.62$ & 2.22 & $9.22 \pm 1.01$ & 10.20 \\
19ad & 19a & -0.66 & $-0.37 \pm 0.18$ & 0.29 & $1.99 \pm 1.05$ & 2.65 \\
19ad & 19ao & -0.90 & $-0.26 \pm 0.35$ & 0.64 & $4.19 \pm 1.25$ & 5.09 \\
19ad & 19ax & 3.48 & $1.02 \pm 0.46$ & 2.46 & $5.83 \pm 1.25$ & 2.34 \\
19ad & 19v & -0.11 & $1.18 \pm 0.33$ & 1.29 & $3.33 \pm 1.17$ & 3.44 \\
19ad & 19z & 0.28 & $0.68 \pm 0.23$ & 0.40 & $1.86 \pm 0.87$ & 1.58 \\
19aj & 19l & -0.32 & $1.06 \pm 0.31$ & 1.38 & $-2.49 \pm 0.09$ & 2.17 \\
19ax & 19at & -4.33 & $-0.98 \pm 0.17$ & 3.35 & $-2.91 \pm 1.25$ & 1.42 \\
19bb & 19az & -0.17 & $-0.99 \pm 0.17$ & 0.82 & $-0.45 \pm 0.39$ & 0.28 \\
19bb & 19bd & -0.64 & $0.15 \pm 0.16$ & 0.79 & $0.35 \pm 0.39$ & 0.99 \\
19d & 19af & -0.16 & $1.51 \pm 0.16$ & 1.67 & $2.18 \pm 0.78$ & 2.34 \\
19s & 19j & 1.34 & $1.14 \pm 0.37$ & 0.20 & $2.95 \pm 1.17$ & 1.62 \\
19v & 19af & -0.02 & $0.27 \pm 0.23$ & 0.29 & $1.20 \pm 0.78$ & 1.21 \\
19v & 19j & 0.12 & $-1.28 \pm 0.28$ & 1.40 & $2.47 \pm 1.17$ & 2.35 \\
\hline & & & MUE & 1.18 & MUE & 2.22 \\
& & & & & &
\end{tabular}


Supplementary Table 5. Calculated and experimental absolite binding affinity ( $\Delta G_{\text {bind }}$ ) for each compound within the FEP dataset (the data is plotted in Figure 6B and Supplementary Figure 1). Errors are defined by the cycle closure correction (CCC) estimated from the FEP pathway shown in Supplementary Figure 2, with the reference compound indicated (REF).

\begin{tabular}{cccccc}
\hline \multirow{2}{*}{ Lig } & Exp & \multicolumn{2}{c}{ Conformation A } & \multicolumn{2}{c}{ Conformation B } \\
& $\Delta G$ bind & $\Delta G$ bind & UE & $\Delta G_{\text {bind }}$ & UE \\
\hline 19a & -10.96 & $-10.31 \pm 0.23$ & 0.65 & $-11.75 \pm 0.98$ & 0.79 \\
19ab & -9.87 & $-9.35 \pm 0.32$ & 0.52 & $-12.88 \pm 1.40$ & 3.01 \\
19ad & -10.30 & $-10.20 \pm 0.43$ & 0.10 & $-13.74 \pm 1.17$ & 3.44 \\
19af & -10.42 & $-8.78 \pm 0.42$ & 1.64 & $-9.21 \pm 0.78$ & 1.21 \\
19aj & -10.32 & $-12.55 \pm 0.54$ & 2.23 & $-8.12 \pm 0.75$ & 2.20 \\
19am & -10.85 & $-12.42 \pm 0.32$ & 1.57 & $-3.66 \pm 1.40$ & 7.19 \\
19ao & -11.20 & $-10.66 \pm 0.43$ & 0.54 & $-9.55 \pm 1.57$ & 1.65 \\
19at & -11.15 & $-10.00 \pm 0.40$ & 1.15 & $-10.83 \pm 1.57$ & 0.32 \\
19ax & -6.82 & $-9.19 \pm 0.38$ & 2.37 & $-7.91 \pm 1.71$ & 1.10 \\
19az & -10.05 & $-11.58 \pm 0.22$ & 1.54 & $-11.69 \pm 0.96$ & 1.64 \\
19bb & -9.88 & $-10.58 \pm 0.28$ & 0.70 & $-11.24 \pm 0.88$ & 1.36 \\
19bd & -10.52 & $-10.52 \pm 0.28$ & 0.00 & $-10.88 \pm 0.96$ & 0.36 \\
19d & -10.27 & $-10.20 \pm 0.34$ & 0.06 & $-11.39 \pm 1.24$ & 1.13 \\
19j & -10.29 & $-10.40 \pm 0.23$ & 0.11 & $-7.94 \pm 1.17$ & 2.35 \\
19l & -10.64 & $-11.18 \pm 0.54$ & 0.54 & $-10.61 \pm 0.75$ & 0.03 \\
19s & -11.62 & -11.62 & $(R E F)$ & $-10.89 \pm 1.65$ & 0.73 \\
19v & -10.41 & $-9.14 \pm 0.329$ & 1.27 & -10.41 & $(R E F)$ \\
19z & -10.02 & $-9.45 \pm 0.356$ & 0.57 & $-11.88 \pm 1.30$ & 1.86 \\
\hline & & $M U E$ & 0.92 & MUE & 1.77
\end{tabular}




\section{HPLC traces for lead compounds}

Project Name Rubén Prieto

Reported by User: Breeze user (Breeze)

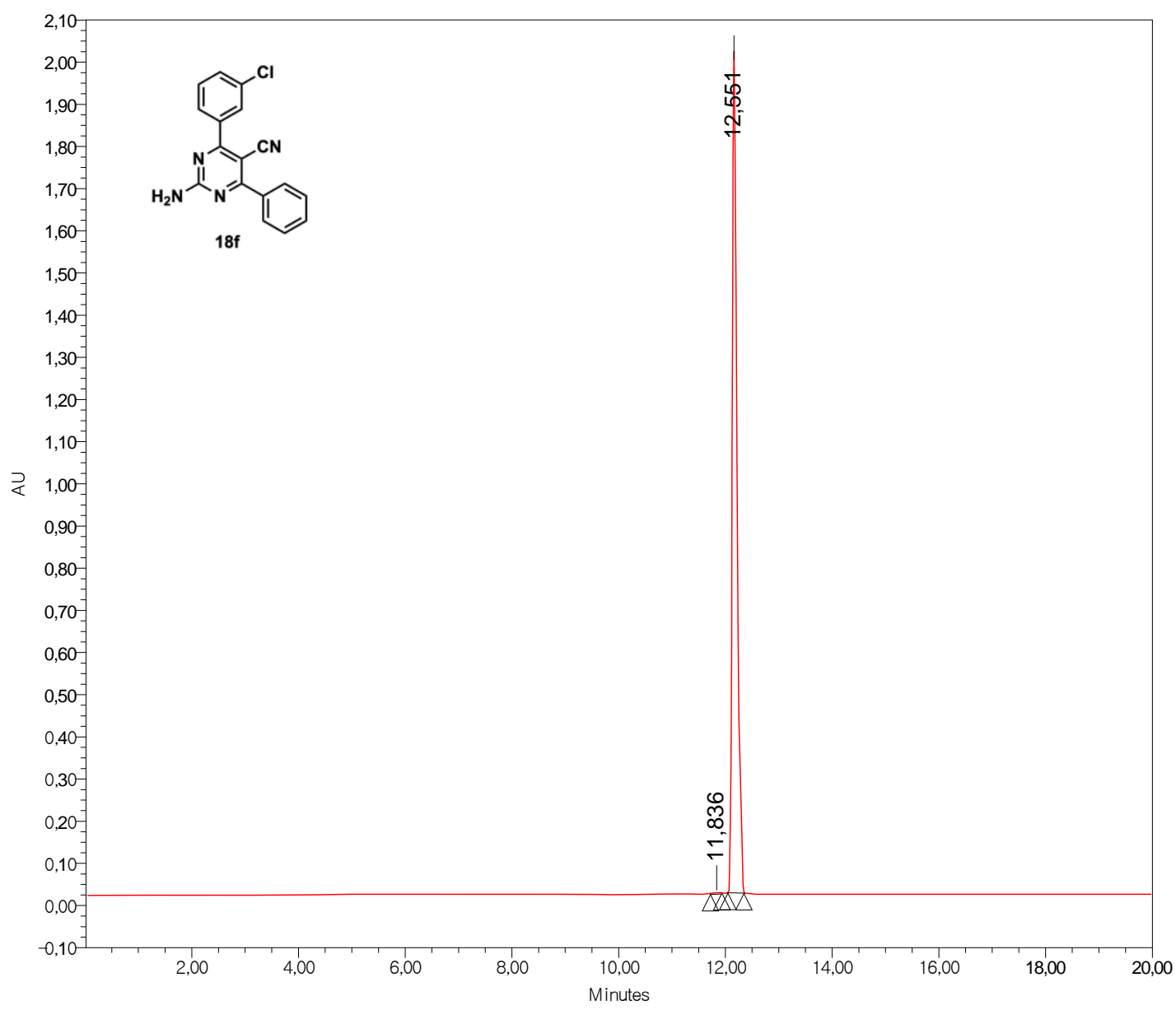

Sample Name: 18f; Date Acquired: 25/02/2021 11:15:52 CET; Vial: 1; Injection: 1

Peak Summary with Statistics

Peak Name:

\begin{tabular}{|c|c|l|r|r|r|r|r|}
\hline & $\begin{array}{c}\text { Sample } \\
\text { Name }\end{array}$ & Vial & Inj. & $\begin{array}{c}\text { RT } \\
(\mathrm{min})\end{array}$ & $\begin{array}{c}\text { Area } \\
(\mu \vee * \text { *ec })\end{array}$ & \% Area & $\begin{array}{c}\text { Height } \\
(\mu \mathrm{V})\end{array}$ \\
\hline 1 & $18 \mathrm{f}$ & 1 & 1 & 12,551 & 24163640,67 & 99,50 & 4004378 \\
\hline 2 & $18 \mathrm{f}$ & 1 & 1 & 11,836 & 121425,33 & 0,50 & 212118 \\
\hline Mean & & & & 12,194 & 12142533 & & 2012769 \\
\hline Std. Dev. & & & & 505,5 & 17000413,5 & & 2816487,63 \\
\hline \% RSD & & & & 4,14 & 140,01 & & 139,931 \\
\hline
\end{tabular}

Report Method: Peak Summary Report

Printed: $03 / 09 / 2021$

Page: 1 of 2

17:40:22 Europe/Madrid 
Project Name Rubén Prieto

Reported by User: Breeze user (Breeze)

\section{Acquisition Log}

$\begin{array}{ll}\text { Acquired By } & \text { Breeze } \\ \text { Injection } & 1 \\ \text { Date Acquired } & \text { 25/02/2021 11:15:52 CET } \\ \text { Run Time } & \text { 20,00(Minutes) } \\ \text { Aca Method Set } & \text { 20\%DCMIPAGradF1 set } \\ \text { Injection Volume } & 20,00 \text { (uL) } \\ \text { Injection Id } & 1600 \\ \text { Instrument Method Name } & 20 \% \text { DCMIPAGradF1 } \\ \text { Superseded } & \text { No }\end{array}$


Project Name Rubén Prieto

Reported by User: Breeze user (Breeze)

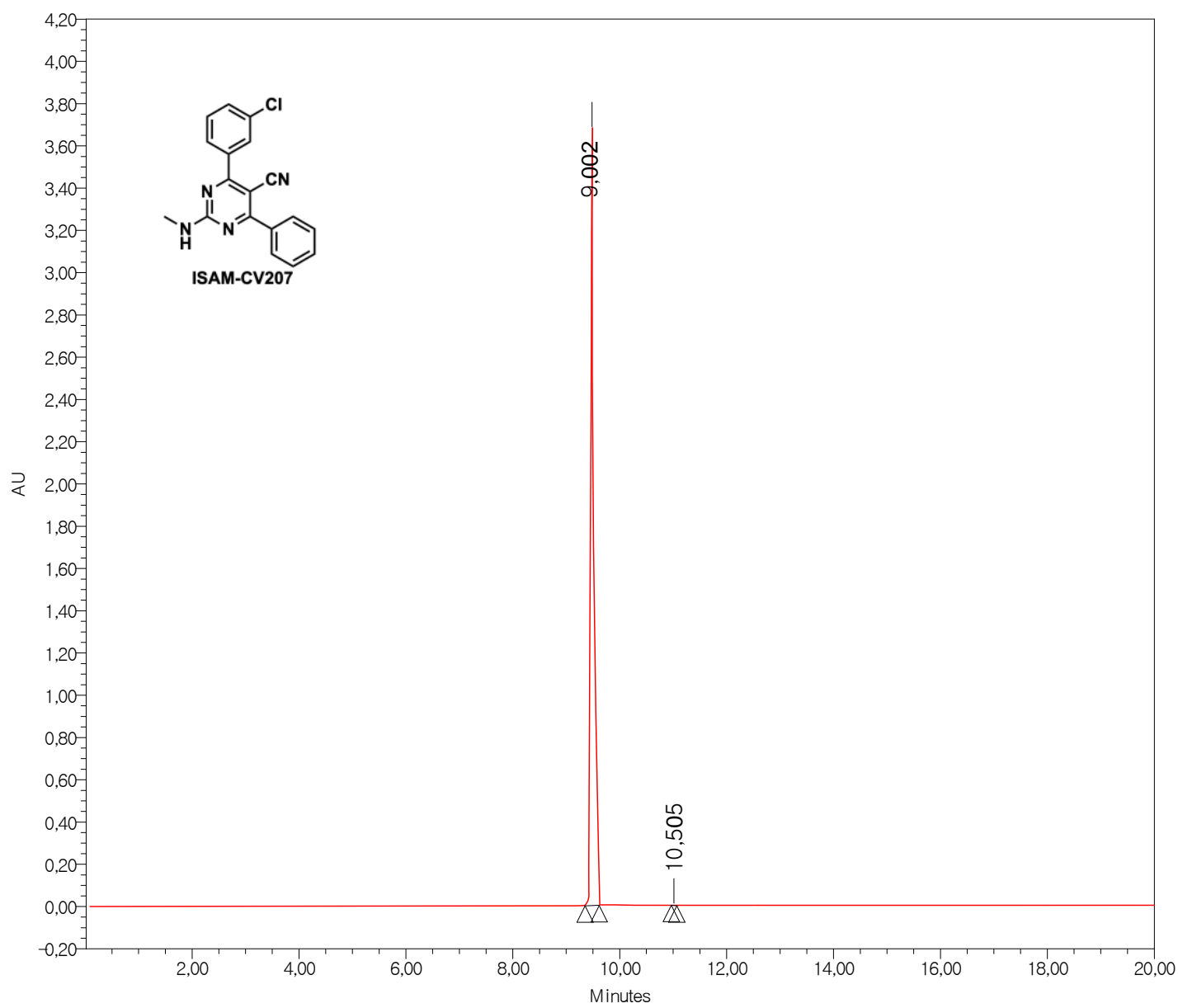

Sample Name: ISAM-CV207; Date Acquired: 25/02/2021 12:16:23 CET; Vial: 1; Injection: 1

Peak Summary with Statistics

Peak Name:

\begin{tabular}{|c|c|c|r|r|r|r|r|}
\hline & $\begin{array}{c}\text { Sample } \\
\text { Name }\end{array}$ & Vial & Inj. & $\begin{array}{c}\text { RT } \\
(\mathrm{min})\end{array}$ & $\begin{array}{c}\text { Area } \\
(\mu \mathrm{V} * \mathrm{sec})\end{array}$ & $\%$ Area & \multicolumn{1}{c|}{$\begin{array}{c}\text { Height } \\
(\mu \mathrm{V})\end{array}$} \\
\hline 1 & ISAM-CV207 & 1 & 1 & 9,002 & 51410697 & 99,98 & 8008756 \\
\hline 2 & ISAM-CV207 & 1 & 1 & 10,505 & 103027 & 0,02 & 2121 \\
\hline Mean & & & & 9,754 & 25756862 & & 4005439 \\
\hline Std. Dev. & & & & 1,062 & 36280001,35 & & 5661545,9 \\
\hline \% RSD & & & & 10,8 & 140,85 & & 141,346 \\
\hline
\end{tabular}

Report Method: Peak Summary Report

Printed: $03 / 09 / 2021$

Page: 1 of 2

17:42:21 Europe/Madrid 
Project Name Rubén Prieto

Reported by User: Breeze user (Breeze)

\section{Acquisition Log}

$\begin{array}{ll}\text { Acquired By } & \text { Breeze } \\ \text { Injection } & 1 \\ \text { Date Acquired } & \text { 25/02/2021 12:16:23 CET } \\ \text { Run Time } & \text { 20,00(Minutes) } \\ \text { Acq Method Set } & \text { 20\%DCMIPAGradF1 set } \\ \text { Injection Volume } & 20,00 \text { (uL) } \\ \text { Injection Id } & 1601 \\ \text { Instrument Method Name } & 20 \% \text { DCMIPAGradF1 } \\ \text { Superseded } & \text { No }\end{array}$


Project Name Rubén Prieto

Reported by User: Breeze user (Breeze)

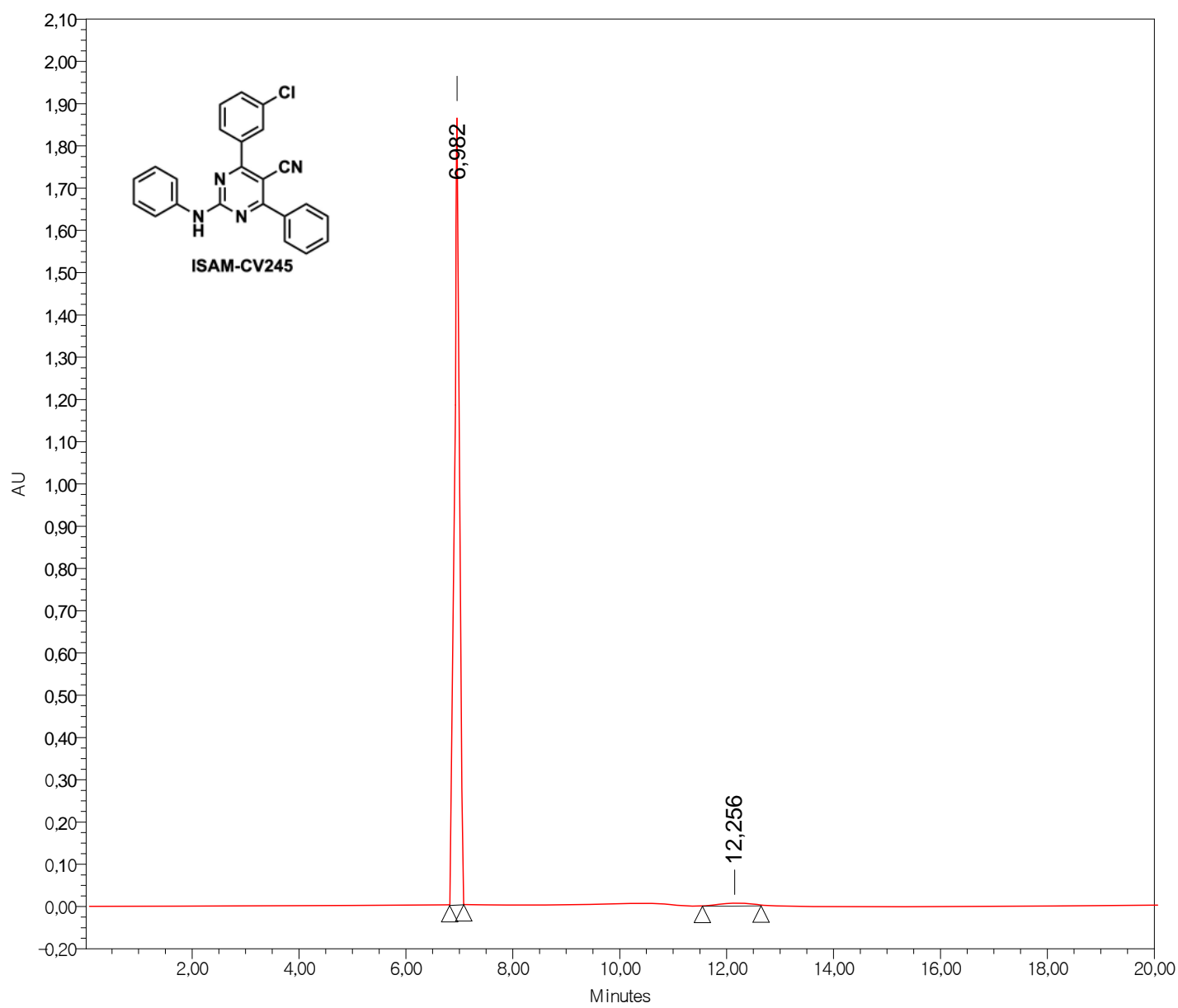

Sample Name: ISAM-CV245; Date Acquired: 25/02/2021 12:22:22 CET; Vial: 1; Injection: 1

Peak Summary with Statistics

Peak Name:

\begin{tabular}{|c|c|c|r|r|r|r|r|}
\hline & $\begin{array}{c}\text { Sample } \\
\text { Name }\end{array}$ & Vial & Inj. & $\begin{array}{c}\text { RT } \\
(\mathrm{min})\end{array}$ & $\begin{array}{c}\text { Area } \\
(\mu \mathrm{V} * \mathrm{sec})\end{array}$ & $\%$ Area & \multicolumn{1}{c|}{$\begin{array}{c}\text { Height } \\
(\mu \mathrm{V})\end{array}$} \\
\hline 1 & ISAM-CV245 & 1 & 1 & 6,928 & 23354666 & 97,75 & 4005211 \\
\hline 2 & ISAM-CV245 & 1 & 1 & 12,256 & 5375754 & 2,25 & 42121 \\
\hline Mean & & & & 9,592 & 14365211 & & 2023666 \\
\hline Std. Dev. & & & & 3,767 & 12713010,83 & & 2802327,81 \\
\hline \% RSD & & & & 39,3 & 88,50 & & 138,477 \\
\hline
\end{tabular}

Report Method: Peak Summary Report

Printed: $03 / 09 / 2021$

Page: 1 of 2 18:10:22 Europe/Madrid 
Project Name Rubén Prieto

Reported by User: Breeze user (Breeze)

\section{Acquisition Log}

$\begin{array}{ll}\text { Acquired By } & \text { Breeze } \\ \text { Injection } & 1 \\ \text { Date Acquired } & \text { 25/02/2021 12:22:22 CET } \\ \text { Run Time } & \text { 20,00(Minutes) } \\ \text { Acq Method Set } & \text { 20\%DCMIPAGradF1 set } \\ \text { Injection Volume } & 20,00 \text { (uL) } \\ \text { Injection Id } & 1602 \\ \text { Instrument Method Name } & 20 \% \text { DCMIPAGradF1 } \\ \text { Superseded } & \text { No }\end{array}$

Report Method: Peak Summary Report

Printed: 03/09/2021

Page: 2 of 2

18:10:22 Europe/Madrid 


\section{References}

(1) Cheng, R. K. Y.; Segala, E.; Robertson, N.; Deflorian, F.; Doré, A. S.; Errey, J. C.; Fiez-Vandal, C.; Marshall, F. H.; Cooke, R. M. Structures of Human $\mathrm{A}_{1}$ and A2A Adenosine Receptors with Xanthines Reveal Determinants of Selectivity. Structure 2017, 25, 1275-1285.

(2) Areias, F.; Costa, M.; Castro, M.; Brea, J.; Gregori-Puigjané, E.; Proença, M. F.; Mestres, J.; Loza, M. I. New Chromene Scaffolds for Adenosine A $2 \mathrm{~A}$ Receptors: Synthesis, Pharmacology and Structure-Activity Relationships. Eur. J. Med. Chem. 2012, 54, 303-310.

(3) El Maatougui, A.; Azuaje, J.; González-Gómez, M.; Miguez, G.; Crespo, A.; Carbajales, C.; Escalante, L.; García-Mera, X.; Gutiérrez-De-Terán, H.; Sotelo, E. Discovery of Potent and Highly Selective $A_{2 B}$ Adenosine Receptor Antagonist Chemotypes. J. Med. Chem. 2016, 59, 1967-1983.

(4) Yaziji, V.; Rodríguez, D.; Gutiérrez-De-Terán, H.; Coelho, A.; Caamaño, O.; García-Mera, X.; Brea, J.; Loza, M. I.; Cadavid, M. I.; Sotelo, E. Pyrimidine Derivatives as Potent and Selective $\mathrm{A}_{3}$ Adenosine Receptor Antagonists. J. Med. Chem. 2011, 54, 457-471. 